SFB 649 Discussion Paper 2014-045

\title{
Optimal Sales Contracts with Withdrawal Rights
}

\author{
Daniel Krähmer* \\ Roland Strausz**
}

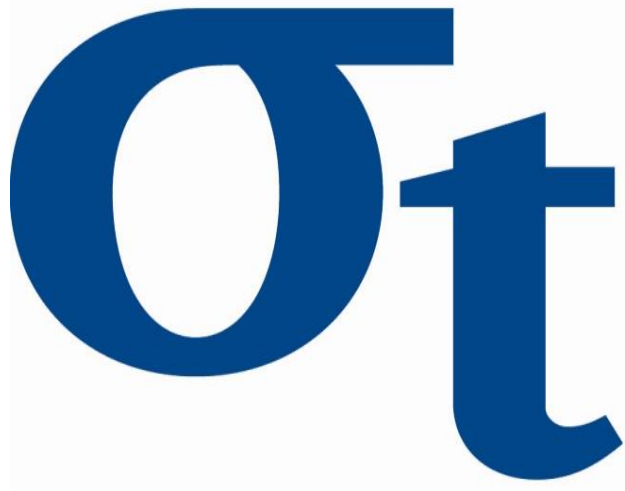

a

$\checkmark$

6

* Universität Bonn, Germany

** Humboldt-Universität zu Berlin, Germany

This research was supported by the Deutsche Forschungsgemeinschaft through the SFB 649 "Economic Risk".

http://sfb649.wiwi.hu-berlin.de ISSN 1860-5664 


\title{
Optimal Sales Contracts with Withdrawal Rights
}

\author{
Daniel Krähmer*and Roland Strausz ${ }^{\dagger}$
}

July 20, 2014

\begin{abstract}
We introduce ex post participation constraints in the standard sequential screening model. This captures the presence of consumer withdrawal rights as, for instance, mandated by EU regulation of "distance sales contracts". With such additional constraints, the optimal contract is static and, unlike with only ex ante participation constraints, does not elicit the agent's information sequentially. With ex post participation constraints it is insufficient to consider only local incentive constraints. We develop a novel technique to identify the relevant global constraints.
\end{abstract}

Keywords: Sequential screening, dynamic mechanism design, participation constraints, Mirrlees approach

JEL codes: D82, H57

${ }^{*}$ Universität Bonn, Institute for Microeconomics, Adenauer Allee 24-42, D-53113 Bonn (Germany), kraehmer@hcm.uni-bonn.de.

${ }^{\dagger}$ Humboldt-Universität zu Berlin, Institute for Economic Theory 1, Spandauer Str. 1, D-10178 Berlin (Germany), strauszr@wiwi.hu-berlin.de. An earlier version of this paper circulated under the title "The Benefits of Sequential Screening". We thank three anonymous referees and the editor Marco Ottaviani as well as Andreas Asseyer, Marco Battaglini, Moritz Brinkmann, Yeon-Koo Che, Rahul Deb, Peter Esö, Thomas Gehrig, Anke Gerber, Li Hao, Martin Pollrich, Urs Schweizer, and seminar participants at Bonn, Mannheim, NYU, Paris, UBC, Yale, and Zurich. We gratefully acknowledge financial support by the DFG (German Science Foundation) under SFB/TR-15 and SFB649. 


\section{Introduction}

On the 12th of December 2011 the European directive 2011/83/EU was adopted, harmonizing earlier legislation on "distance sales contracts". These contracts govern internet and mail order sales to consumers in the EU, a market which in 2011 represented about $10 \%$ of all retail business. ${ }^{1}$ As the share of internet sales is expected to rise steadily in the coming years, the economic impact of the legislation increases further. ${ }^{2}$

Governing distance sales contracts, the directive mandates a withdrawal right for consumers of two weeks. Section 37 clarifies that the goal behind this withdrawal right is to establish a level playing field between internet shops and traditional mortar and bricks stores by ensuring that consumers can make their final buying decision on the same informational basis: "Since in the case of distance sales, the consumer is not able to see the goods before concluding the contract, he should have a right of withdrawal. For the same reason, the consumer should be allowed to test and inspect the goods he has bought to the extent necessary to establish the nature, characteristics and the functioning of the goods" (Section 37 of 2011/83/EU).

Hence, legislators view internet consumers at the following disadvantage: While a consumer who buys on the internet, signs the sales contract before being able to ascertain the nature and functioning of a good, a similar consumer who buys at a traditional store, signs his or her sales contract after obtaining this information. ${ }^{3}$ The intention of the directive is to rectify this difference by giving the consumer a withdrawal right.

We investigate the economic effects of withdrawal rights on optimal sales contracts. In particular, we ask whether the EU regulation achieves its objective to level the playing field between traditional and internet sales. To compare the optimal selling contracts under the two different selling modes, we model the selling problem of a traditional store

\footnotetext{
${ }^{1}$ Figures taken from http://www.retailresearch.org/onlineretailing.php (last retrieved 19.04.2013).

${ }^{2}$ According to The Economist (edition of July 13th 2013), referring to a study of AXA Real Estate, a property management firm, 90\% of growth in retail sales expected until 2016 in Britain, Germany and France will be online.

${ }^{3}$ Section 31 of the directive makes this point even more explicitly: "In order to ascertain the nature and functioning of a good, the consumer should only handle or try it in the same manner as he would be allowed to do in a shop. For example, the consumer should only try on a garment and should not be allowed to wear it."
} 
as a static screening problem in the tradition of Baron and Myerson (1986), where the buyer, before signing the contract, has received all relevant private information. It is well known that in the static screening problem, a posted price contract is the optimal selling contract. In line with the view of EU regulators, we interpret internet sales as a sequential screening problem in the sense of Courty and Li (2000), where the consumer learns additional private information about his valuation after signing the contract.

For the standard sequential screening model, the optimal selling contract is dynamic in that it screens the buyer over time. ${ }^{4}$ In this model the buyer has only an ex ante outside option and is bound by the contract even if ex post, after new information has arrived, this imposes losses on him. We argue that the inclusion of withdrawal rights, as mandated by the EU regulation, is equivalent to introducing ex post participation constraints in the sequential screening model, implying that the buyer can sustain no (or only limited) losses ex post. The main result of our paper is that, even though sequential screening is still feasible with ex post participation constraints, the seller no longer benefits from it. Instead, the optimal selling contract is static and coincides with the optimal posted price contract in the static screening model. In this sense, the EU regulation achieves its goal of leveling the playing fields between traditional and internet shops. ${ }^{5}$

We emphasize that our results extend beyond the context of distance sales contracts to other dynamic principal agent relationships where, possibly weaker, ex post participation constraints matter. ${ }^{6}$ In particular, we show that our results remain valid in applications where the difference between ex ante and ex post outside option is not too large, or where the agent can sustain some losses ex post allowing him to post a limited, non-refundable bond ex ante. ${ }^{7}$

4 The (strict) optimality of sequential screening in the absence of ex post participation constraints figures most prominently in Courty and Li (2000), but also features in Baron and Besanko (1984), Battaglini (2005), Boleslavsky and Said (2013), Dai et al. (2006), Esö and Szentes (2007a, b), Inderst and Peitz (2012), Hoffmann and Inderst (2011), Krähmer and Strausz (2011), Nocke et al. (2011) and Pavan et al. (2014).

${ }^{5}$ As we discuss in Subsection 3.2.2, the welfare effects of the regulation are, however, ambiguous.

${ }^{6}$ See also Sappington (1983) or Gresik (1991), who stress the importance of ex post participation constraints in static adverse selection models.

${ }^{7}$ We also show that our result remains true in the context of distance sales when the buyer has to bear small costs for returning an order he does not like. 
One such application is the employment relation. Employees typically learn important private information about the disutility of the job only ex post after having joined the firm, and in most countries, employees have the legal right to resign from the contract at any time. Moreover, outside options in the form of alternative job opportunities tend to be comparable ex ante and ex post. Importantly, "non-slavery" laws prohibit the employer from demanding, either ex- or implicitly, a non-refundable signing bond by the employee that would restrain the worker's withdrawal decision. ${ }^{8}$ Another application is the procurement relationship. Unfavorable private ex post information, such as cost overruns, may force the supplier to file for bankruptcy before completing the contract. Limited liability on the supplier's side and bankruptcy law restrict the procurer's ability to extract payments or seize assets from an insolvent supplier. From the procurer's perspective, bankruptcy thus constitutes an ex post outside option of the contractor. The procurement industry is well aware of this problem, and it is common to require "performance bonds" which are paid up-front and returned to the supplier only upon contract completion. Cash-constraints and imperfect capital markets, however, place limits on such bonds. ${ }^{9}$

To shed light on our result, it is easiest to consider the case that the seller's costs are zero, so that trade is always efficient, and the seller offers the buyer a menu of option contracts. An option contract consists of an up-front payment by the buyer, and gives the buyer the option to purchase the good at a pre-specified exercise price after having observed his true valuation. Our result that with ex post participation constraints the seller does not benefit from screening the buyer sequentially means that offering a menu containing different option contracts is not optimal.

\footnotetext{
${ }^{8}$ E.g., the California Labor Code Section 402 explicitly states "No employer shall demand, exact, or accept any cash bond from any employee or applicant". Likewise, employment bonds are prohibited under German law, including the retainment of unpaid wages after a worker's resignation (see ruling BAG 06.09.1989 - 5 AZR 586/88). Some context specific exceptions exist such as deposits when the employee is entrusted with the employer's property, or "training bonds", where the employer makes a costly, non-specific human capital investment in the employee.

${ }^{9}$ In addition, for the case that a supplier breaches the contract and quits, the law often explicitly allows courts to reduce penalties that are considered as out of proportion. See, e.g., the US Uniform Civil Code §2-718: "A term fixing unreasonably large liquidated damages is void as a penalty"; or the German Civil Code §343: "If a payable penalty is disproportionately high, it may on the application of the obligor be reduced to a reasonable amount by judicial decision."
} 
To gain intuition for this, assume to the contrary that, at the optimum, different ex ante buyer types select different option contracts. Observe first that when the buyer's true valuation happens to equal the exercise price, the buyer obtains a net payoff of zero from consumption. Therefore, with ex post participation constraints, the seller cannot demand a positive up-front fee, because this would cause an ex post loss if the buyer's true valuation equals the exercise price. This then means that any option contract from the menu is individually rational for any ex ante type.

Now consider the contract in the menu with the highest exercise price. This contract generates less surplus than any other contract and, by incentive compatibility, yields any type who picks it, a weakly higher rent than any of the more efficient contracts. But this implies that the seller is better off excluding this contract from the menu so that the buyer must pick one that generates more surplus, while paying him lower rents (but, as argued, is also individually rational). By this argument it is optimal to delete any but the most efficient contract from the menu. Therefore, with ex post participation constraints, it is optimal not to screen ex ante types. ${ }^{10}$

The above reasoning only applies to option contracts. Our main conceptual contribution is to derive sufficient conditions under which option contracts are indeed optimal. As we will argue, this is equivalent to showing that the optimal contract is deterministic. In the absence of ex post participation constraints, the optimality of deterministic contracts can be established by considering a relaxed problem in the spirit of Mirrlees, which only considers the "local" ex ante incentive constraints. Under appropriate regularity conditions, the solution to the relaxed problem is automatically deterministic and globally incentive compatible. ${ }^{11}$ We show that in our case, such a local approach does not work, because one cannot find a regularity condition so that the solution to the corresponding relaxed problem is automatically deterministic. ${ }^{12}$ Instead, we develop a novel technique

\footnotetext{
${ }^{10}$ This argument fails if there are only ex ante participation constraints. In this case, the seller charges a high (strictly positive) up-front fee for the contract with the lowest exercise price so that it is acceptable only for the buyer who is most optimistic about his future valuation. The more pessimistic buyers would make an expected loss from this contract. Hence, only offering the most efficient contract in the menu would violate ex ante participation constraints of all but the most optimistic type.

${ }^{11}$ For sequential screening models, this regularity condition was first identified by Courty and Li (2000). Most of the literature mentioned in footnote 4 adopts these or closely related conditions.

${ }^{12}$ Battaglini and Lamba (2014) argue that the failure of the local approach is typical for dynamic
} 
to identify a different relaxed problem, which involves global constraints, whose solution solves the original problem under an appropriate regularity condition. ${ }^{13}$ In addition to the familiar monotone hazard rate which requires the ratio of an ex ante type's cumulative distribution and the same ex ante type's density to be monotone, this condition requires that also the "cross-hazard rate", i.e., the ratio of an ex ante type's cumulative distribution and any other ex ante type's density is monotone.

The rest of this paper is organized as follows. The next section introduces the setup and derives the principal's problem. In Section 3, we solve the principal's problem for the case that she offers a menu of option contracts. Moreover, we discuss welfare effects of withdrawal rights and extend our result to settings with less stringent ex post participation constraints and costly returns. In Section 4, we allow for general, including stochastic, contracts. Section 5 concludes. All proofs that do not appear in the main text are relegated to the appendix.

\section{The setup}

Consider a potential buyer (he) and a seller (she), who has a single unit of a good for sale. The buyer's valuation of the good is $\theta \in[0,1]$ and the seller's opportunity costs are commonly known to be $c \in[0,1)$. Trade is therefore efficient for at least the valuation $\theta=1$. The terms of trade specify whether the good is exchanged and payments from the buyer to the seller. The parties are risk neutral and have quasi-linear utility functions. That is, the seller's profit is payments minus her opportunity costs, and the buyer's utility is valuation minus payments.

At the time of contracting about the terms of trade, no party knows the buyer's true valuation, $\theta$, but the buyer has private information about its distribution. After the seller offers the contract, the buyer privately learns his true valuation $\theta \cdot{ }^{14}$ Formally, there are two periods. In period 1 , the buyer knows his valuation is distributed according to distribution function $G_{i}$ with non-shifting support [0,1], where $i$ is drawn from the set mechanism design problems.

${ }^{13}$ Our technique requires to consider sequential screening with finite ex ante types. However, as our result holds for any number of ex ante types, we can regard the continuous types case as a limiting case.

${ }^{14}$ In the context of distance sales, the good is shipped to the buyer who learns $\theta$ upon inspecting and trying out the good. 
$I \equiv\{1, \ldots, n\}$ with probability $p_{i}>0$. We refer to $i$ as the buyer's ex ante type. In period 2 , the buyer observes his ex post type $\theta$ which is drawn according to $G_{i}$. While the buyer's ex ante and ex post types are his private information, the distributions of ex ante and ex post types are common knowledge. ${ }^{15}$

\section{$2.1 \quad$ Seller's problem}

The seller's problem is to design a contract that maximizes her expected profits. By the revelation principle for sequential games (e.g., Myerson 1986), the optimal contract can be found in the class of direct and incentive compatible contracts which, on the equilibrium path, induce the buyer to report his type truthfully. Formally, a direct contract

$$
(\mathbf{x}, \mathbf{t})=\left(x_{j}\left(\theta^{\prime}\right), t_{j}\left(\theta^{\prime}\right)\right)_{j \in I, \theta^{\prime} \in[0,1]}
$$

requires the buyer to report an ex ante type $j$ in period 1 , and an ex post type $\theta^{\prime}$ in period 2. A contract commits the seller to a selling schedule $x_{j}\left(\theta^{\prime}\right)$ and a transfer schedule $t_{j}\left(\theta^{\prime}\right)$.

If the buyer's true ex post type is $\theta$ and his period 1 report was $j$, then his utility from reporting $\theta^{\prime}$ in period 2 is

$$
v_{j}\left(\theta^{\prime} ; \theta\right) \equiv \theta x_{j}\left(\theta^{\prime}\right)-t_{j}\left(\theta^{\prime}\right) .
$$

With slight abuse of notation, we denote the buyer's period 2 utility from truth-telling by

$$
v_{j}(\theta) \equiv v_{j}(\theta ; \theta)
$$

The contract is incentive compatible in period 2 if it gives the buyer an incentive to announce his ex post type truthfully:

$$
v_{j}(\theta) \geq v_{j}\left(\theta^{\prime} ; \theta\right) \text { for all } j \in I, \theta, \theta^{\prime} \in[0,1]
$$

If the contract is incentive compatible in period 2, the buyer announces his ex post type truthfully no matter what his report in the first period. ${ }^{16}$ Hence, if the buyer's true ex

\footnotetext{
${ }^{15}$ Our assumption that ex post types are continuous and ex ante types are discrete is for technical convenience only. Note that we allow for an arbitrary number of ex ante types.

${ }^{16}$ Because the buyer's period 2 utility is independent of his ex ante type, a contract which is incentive compatible in period 2 automatically induces truth-telling in period 2 also off the equilibrium path, that is, if the buyer has misreported his ex ante type in period 1.
} 
ante type is $i$, then his period 1 utility from reporting $j$ is

$$
u_{j i} \equiv \int_{0}^{1} v_{j}(\theta) d G_{i}(\theta)
$$

The contract is incentive compatible in period 1 if it induces the buyer to announce his ex ante type truthfully:

$$
u_{i i} \geq u_{j i} \quad \text { for all } i, j \in I \text {. }
$$

Our main objective is to analyze the case in which the buyer has a withdrawal right. This means that, after having observed his valuation $\theta$, the buyer has the choice between continuing with the trade as specified in the contract, or withdrawing from it and obtaining his outside option of 0 . The withdrawal right effectively guarantees the buyer a utility of 0 for any realization of his ex post valuation. Accordingly, with withdrawal rights, the contract needs to satisfy the ex post individual rationality constraints: ${ }^{17}$

$$
v_{i}(\theta) \geq 0 \quad \text { for all } i \in I, \theta \in[0,1] \text {. }
$$

In contrast, an incentive compatible contract is ex ante individually rational if

$$
u_{i i} \geq 0 \quad \text { for all } i \in I \text {. }
$$

Clearly, ex post individual rationality implies ex ante individual rationality. ${ }^{18}$

We say a contract is feasible (with withdrawal rights) if it is incentive compatible in both periods and both ex post and ex ante individually rational.

The seller's payoff from a feasible contract is the difference between transfer and costs, or equivalently the difference between aggregate surplus and the buyer's utility. That is, if the buyer's ex ante type is $i$, the seller's conditional expected payoff is

$$
w_{i}=\int_{0}^{1} t_{i}(\theta)-c x_{i}(\theta) d G_{i}(\theta)=\int_{0}^{1}[\theta-c] x_{i}(\theta)-v_{i}(\theta) d G_{i}(\theta) .
$$

\footnotetext{
${ }^{17}$ Put differently, if the seller offered a contract for which the buyer would make an ex post loss for some $\theta$, then the buyer would withdraw from the contract for such a $\theta$, and effectively enforce the terms of trade $x_{i}(\theta)=t_{i}(\theta)=0$.

${ }^{18}$ In Section 3.3, we consider the case in which the ex post and ex ante outside options differ and show that our results are robust if the difference is not too large.
} 
The seller's problem is therefore to find a direct contract $\left(\mathbf{x}^{*}, \mathbf{t}^{*}\right)$ that solves the following maximization problem:

$$
\mathcal{P}: \quad \max _{(\mathbf{x}, \mathbf{t})} \sum_{i \in I} p_{i} w_{i} \quad \text { s.t. } \quad(2),(3),(4),
$$

where we disregard (5) because it is implied by (4).

Our main result is that with withdrawal rights, the seller does not benefit from sequential screening but optimally offers a static contract that does not condition on the buyer's ex ante type. That is, $\mathcal{P}$ exhibits a solution with $x_{i}=\bar{x}$ and $t_{i}=\bar{t}$ for all $i \in I$. We refer to a feasible contract that is independent of the ex ante type as static. A static contract $(\overline{\mathbf{x}}, \overline{\mathbf{t}})=((\bar{x}, \bar{t}), \ldots,(\bar{x}, \bar{t}))$ yields the seller a payoff

$$
\bar{w}=\sum_{i} p_{i} \int_{0}^{1} \bar{t}(\theta)-c \bar{x}(\theta) d G_{i}(\theta)=\int_{0}^{1} \bar{t}(\theta)-c \bar{x}(\theta) d \bar{G}(\theta),
$$

where $\bar{G}(\theta) \equiv \sum_{i} p_{i} G_{i}(\theta)$ is the average ex ante distribution over types.

Because a static contract is trivially incentive compatible in period 1, the optimal static contract $(\overline{\mathbf{x}}, \overline{\mathbf{t}})$ maximizes $\bar{w}$ subject to the incentive constraints $(2)$ and the ex post individual rationality constraint (4). This is a standard unit good screening problem, and it is well known from, for example, Riley and Zeckhauser (1983), that the seller's optimal selling policy is to offer the good at a take-it-or-leave-it price $\bar{R}$ that solves

$$
\max _{R}(1-\bar{G}(R))(R-c)
$$

We assume that an optimal static contract exists, which means a maximizer $\bar{R}$ exists.

We will show that offering the good at the price $\bar{R}$ remains the optimal policy for the sequential screening problem $\mathcal{P}$. In the next section, we first show this result for the case that the seller can only offer deterministic contracts. We point out that our result for deterministic contracts does not require any stronger assumptions on the distributions $p$ and $G_{i}$ than those stated in the second paragraph of this section (and that an optimal static contract exists). In particular, we do not need to impose any of the regularity conditions on the distributions $p$ or $G_{i}$ that are commonly used in the literature. In fact, we could, at the cost of some additional notation, even dispense with the assumption that all distributions $G_{i}$ have a common support and ex ante types are discrete. In Section 4, we then derive conditions on the distributions so that deterministic contracts are indeed optimal. 


\section{Deterministic contracts and option contracts}

In this section, we consider the case that the seller is restricted to choose a deterministic contract which exhibits deterministic selling schedules

$$
x_{i}(\theta) \in\{0,1\} \quad \text { for all } i \in I, \theta \in \Theta .
$$

Our result can be best understood by exploiting an insight of the sequential screening literature that an incentive compatible, deterministic contract can be indirectly implemented by a menu of option contracts. Under an option contract $(F, R)$, the buyer pays the seller the up-front fee $F \in \mathbb{R}$ in period 1 and receives the option to buy the good at the exercise price $R \in[0,1]$ in period 2 after having learned $\theta$. We say that a menu of $n$ option contracts,

$$
(\mathbf{F}, \mathbf{R})=\left(\left(F_{1}, R_{1}\right), \ldots,\left(F_{i}, R_{i}\right), \ldots,\left(F_{n}, R_{n}\right)\right)
$$

is incentive compatible if choosing option contract $\left(F_{i}, R_{i}\right)$ from the menu is optimal for buyer type $i$.

When buyer type $i$ has chosen contract $\left(F_{j}, R_{j}\right)$ and observed his valuation $\theta$, he exercises the option only if $\theta$ exceeds the exercise price. Hence, the contract yields him the ex post utility ${ }^{19}$

$$
V_{j}(\theta)= \begin{cases}-F_{j}+\left(\theta-R_{j}\right) & \text { if } \theta \geq R_{j} \\ -F_{j} & \text { otherwise }\end{cases}
$$

Buyer type $i$ 's ex ante utility from the contract $\left(F_{j}, R_{j}\right)$ is

$$
U_{j i}=-F_{j}+\int_{R_{j}}^{1} \theta-R_{j} d G_{i}(\theta) .
$$

Thus, the menu is incentive compatible if for all $i, j \in I$ :

$$
U_{i i} \geq U_{j i}
$$

The next lemma establishes an equivalence between incentive compatible, deterministic contracts and menus of option contracts in terms of implementable outcomes.

\footnotetext{
${ }^{19}$ We denote the utilities associated with option contracts with capital letters and utilities associated with direct contracts with small letters.
} 
Lemma 1 For any direct, incentive compatible, deterministic contract $(\mathbf{x}, \mathbf{t})$, there is an equivalent incentive compatible menu $(\mathbf{F}, \mathbf{R})$ which implements the same outcome as the direct contract and vice versa.

The equivalence is a direct consequence of the well-known fact that incentive compatibility in period 2 requires the selling schedule to be monotone. For deterministic selling schedules, this implies that there exists a cutoff $R_{i}$ in the unit interval where the schedule $x_{i}$ jumps from 0 to 1 . This cutoff corresponds to the exercise price of the option contract, and the utility of the lowest valuation type, taken negatively, $-v_{i}(0)$, corresponds to the up-front fee $F_{i}$.

When the buyer has a withdrawal right, feasible contracts must respect the ex post individual rationality constraints, which, in terms of option contracts, means $V_{i}(\theta) \geq 0$ for $i$ and $\theta$. Because the minimum of $V_{i}(\theta)$ is $-F_{i}$, an option contract is ex post individually rational if and only if $-F_{i} \geq 0$ for all $i$. Consequently, we say that an incentive compatible menu of option contracts $(\mathbf{F}, \mathbf{R})$ is ex post individually rational if and only if for all $i \in I$ :

$$
F_{i} \leq 0
$$

Effectively, the presence of a withdrawal right prevents the seller from using option contracts with a positive up-front fee.

\subsection{Optimal option contracts with withdrawal rights}

The seller's payoff from an option contract is the expected payment minus the cost of the sale, or, equivalently, the difference between the option contract's aggregate surplus and the buyer's utility. Hence, if the buyer's ex ante type is $i$, the seller's conditional expected payoff is

$$
W_{i}=F_{i}-\left(1-G_{i}\left(R_{i}\right)\right)\left(R_{i}-c\right)=\int_{R_{i}}^{1} \theta-c d G_{i}(\theta)-U_{i i}
$$

By Lemma 1, we can represent the optimal deterministic contract as a menu of option contracts $\left(\mathbf{F}^{\mathbf{x p}}, \mathbf{R}^{\mathbf{x p}}\right)$ that solves the problem

$$
\mathcal{P}^{o}: \quad \max _{(\mathbf{F}, \mathbf{R})} \sum_{i} p_{i} W_{i} \quad \text { s.t. } \quad\left(I C_{i j}\right),\left(I R_{i}^{x p}\right) \text { for all } i, j \in I .
$$


In comparison to problem $\mathcal{P}$, the problem $\mathcal{P}^{o}$ does not specify an explicit constraint for incentive compatibility in period 2, because option contracts satisfy this incentive constraint by construction.

Recalling that $\bar{R}$ represents the optimal take-it-or-leave-it price characterizing the optimal static contract, we obtain the following result.

Proposition 1 If the buyer has a withdrawal right so that the seller has to respect the ex post individual rationality constraints $\left(I R_{i}^{x p}\right)$ for all $i \in I$, then an optimal menu $\left(\mathbf{F}^{\mathbf{x p}}, \mathbf{R}^{\mathbf{x p}}\right)$ of option contracts consists of a single contract only: $\left(F_{i}^{x p}, R_{i}^{x p}\right)=(0, \bar{R})$ for all $i \in I$.

To demonstrate the result, we first consider an arbitrary feasible menu $(\mathbf{F}, \mathbf{R})$ and argue that the seller is at least as well off by offering to each type only the option contract in the menu with the smallest exercise price larger than costs but with an up-front fee of zero.

More specifically, let $k=\arg \min _{i}\left\{R_{i} \mid R_{i} \geq c\right\}$ indicate the option contract in the menu $(\mathbf{F}, \mathbf{R})$ with the smallest exercise price larger than costs. ${ }^{20}$ Define the static menu $(\tilde{\mathbf{F}}, \tilde{\mathbf{R}})$ with $\left(\tilde{F}_{i}, \tilde{R}_{i}\right)=\left(0, R_{k}\right)$ for all $i \in I$. Note first that the static menu $(\tilde{\mathbf{F}}, \tilde{\mathbf{R}})$ is evidently feasible with withdrawal rights. We now show that, conditional on any ex ante type $i$, the seller obtains a (weakly) larger profit under the static menu $(\tilde{\mathbf{F}}, \tilde{\mathbf{R}})$ than under the original one $(\mathbf{F}, \mathbf{R})$.

First consider buyer types $i$ who, under the sequential menu, choose a contract that exhibits an exercise price below costs: $R_{i}<c$. By (9) the seller's profit from such a buyer type is

$$
W_{i}=F_{i}+\left(1-G_{i}\left(R_{i}\right)\right)\left(R_{i}-c\right),
$$

which is negative since $F_{i}$ is negative and costs exceed the exercise price. In contrast, the seller's profit from buyer type $i$ under the static menu is non-negative.

Next, consider the other buyer types $i$ who, under the sequential menu, choose a contract that displays an exercise price above costs: $R_{i} \geq c$. Since the original menu is incentive compatible by assumption, buyer type $i$ 's ex ante utility from contract $\left(F_{i}, R_{i}\right)$

\footnotetext{
${ }^{20}$ If such a $k$ does not exist, then the menu $(\mathbf{F}, \mathbf{R})$ yields the seller a loss, because she sells her good below cost, and a static contract with $(F, R)=(0, c)$ does better.
} 
exceeds his utility from contract $\left(F_{k}, R_{k}\right)$, that is, $U_{i i} \geq U_{k i}$. Observe further that the buyer's utility from the contract $\left(\tilde{F}_{i}, \tilde{R}_{i}\right)=\left(0, R_{k}\right)$ is smaller than from the contract $\left(F_{k}, R_{k}\right)$ because they display the same exercise prices, but, since $F_{k} \leq 0$ by $\left(I R_{k}^{x p}\right)$, the latter has a (weakly) smaller up-front fee. Hence,

$$
U_{i i} \geq U_{k i} \geq \tilde{U}_{i i}
$$

where $\tilde{U}_{i i}$ denotes buyer type $i$ 's ex ante utility from the contract $\left(\tilde{F}_{i}, \tilde{R}_{i}\right)=\left(0, R_{k}\right)$. Moreover, since $R_{k}$ is the menu's smallest exercise price exceeding costs, the contract $\left(F_{i}, R_{i}\right)$ yields a smaller surplus than the contract $\left(\tilde{F}_{i}, \tilde{R}_{i}\right)=\left(0, R_{k}\right)$ :

$$
\int_{R_{i}}^{1} \theta-c d G_{i}(\theta) \leq \int_{R_{k}}^{1} \theta-c d G_{i}(\theta) .
$$

The two previous inequalities imply that the seller's profit from the option contract $\left(F_{i}, R_{i}\right)$ is smaller than from $\left(\tilde{F}_{i}, \tilde{R}_{i}\right)$ :

$$
W_{i}\left(F_{i}, R_{i}\right)=\int_{R_{i}}^{1} \theta-c d G_{i}(\theta)-U_{i i} \leq \int_{R_{k}}^{1} \theta-c d G_{i}(\theta)-\tilde{U}_{i i}=W_{i}\left(\tilde{F}_{i}, \tilde{R}_{i}\right) .
$$

Intuitively, the option contract $\left(\tilde{F}_{i}, \tilde{R}_{i}\right)$ yields the seller a larger profit, because it yields both a higher surplus and requires a smaller rent to be paid to the buyer.

We conclude that the static menu $(\tilde{\mathbf{F}}, \tilde{\mathbf{R}})$ yields the seller a (weakly) larger profit than any feasible menu $(\mathbf{F}, \mathbf{R})$. As a result, a static menu consisting of a single option contract with a zero up-front fee must be optimal. Since the seller's profit from such a menu is $(1-\bar{G}(R))(R-c)$, the optimal menu exhibits $F_{i}=0$ and $R_{i}=\bar{R}$ as given by (7). This establishes Proposition 1.

\subsection{Effects of withdrawal rights}

To better understand the role of withdrawal rights, we compare our optimal menu of option contracts to the optimal menu when the buyer does not have withdrawal rights. This will also allow us to discuss the possible welfare effects of the EU withdrawal rights regulation outlined in the introduction. 


\subsubsection{Optimal option contracts without withdrawal rights}

When the buyer does not have a withdrawal right, the seller has to respect only the ex ante individual rationality constraint (5), which in terms of option contracts becomes

$$
U_{i i}=-F_{i}+\int_{R_{i}}^{1} \theta-R_{i} d G_{i}(\theta) \geq 0 .
$$

Courty and $\mathrm{Li}$ (2000) study the problem without withdrawal rights for the case with a continuum of ex ante types and identify natural conditions so that the seller's problem can be solved by the "local Mirrlees" approach. Translated into our setting with discrete ex ante types, this means that the optimal menu of option contracts obtains from solving a relaxed problem where only the (ex ante) individual rationality constraint for the type $i=n$, and the local incentive constraints $I C_{i, i+1}$ are considered. One of the identified conditions is that the distributions $G_{i}$ are ordered in the sense of first order stochastic dominance. In this case, the solution to the relaxed problem represents also a solution to the original problem if the obtained exercise prices are monotonically increasing in the buyer's ex ante type $i$.

Applying the local Mirrlees approach to our setup yields exercise prices $R_{i}^{x a}$ for buyer types $i$ that are implicitly given by the equations

$$
R_{1}^{x a}-c \equiv 0, \quad \text { and } \quad R_{i}^{x a}-c \equiv h_{i}^{x a}\left(R_{i}^{x a}\right) \quad \forall i=2, \ldots, n
$$

where

$$
h_{i}^{x a}(\theta) \equiv \frac{p_{1}+\ldots+p_{i-1}}{p_{i}} \cdot \frac{G_{i}(\theta)-G_{i-1}(\theta)}{g_{i}(\theta)}
$$

is a modified hazard rate that measures the degree of the price distortion due to asymmetric information. ${ }^{21}$

A sufficient condition that ensures the existence and uniqueness of a solution to (10) is that $h_{i}^{x a}(\theta)$ is non-negative (which obtains when $G_{i-1}$ dominates $G_{i}$ in the sense of first order stochastic dominance) and concave in $\theta$. Hence, the remaining question is under

\footnotetext{
${ }^{21}$ Courty and $\mathrm{Li}(2000)$ present a continuous version of this modified hazard rate, while Dai et al. (2006) present it for the case with two ex ante types. Baron and Besanko (1984) were the first to interpret the second factor as an informativeness measure of the ex ante information. Pavan et al. (2014) refer to this measure as an impulse response function and show that it plays a crucial role for dynamic settings in general.
} 
which conditions the exercise prices $R_{i}^{x a}$ are increasing in $i$. A sufficient condition to obtain this ordering is that $h_{i}^{x a}(\theta)$ is increasing in $i$.

Given the exercise prices, the optimal up-front fees are then pinned down by the binding individual rationality constraints for type $n$,

$$
F_{n}^{x a} \equiv \int_{R_{n}^{x a}}^{1} \theta-R_{n}^{x a} d G_{n}(\theta)
$$

and by the binding incentive constraints $I C_{i, i+1}$ for the other types $i<n$ :

$$
F_{i}^{x a} \equiv F_{i+1}^{x a}+\int_{R_{i}^{x a}}^{1} \theta-R_{i}^{x a} d G_{i}(\theta)-\int_{R_{i+1}^{x a}}^{1} \theta-R_{i+1}^{x a} d G_{i}(\theta) .
$$

We summarize these considerations in the next lemma which is a restatement of the result of Courty and Li (2000) with discrete ex ante types.

Lemma 2 (Courty and $\mathrm{Li}$ (2000)) Suppose $G_{i-1}$ dominates $G_{i}$ in the sense of first order stochastic dominance for all $i=2, \ldots, n$, that $h_{i}^{x a}(\theta)$ is concave in $\theta$ and increasing in $i$. Then, if the seller has to respect only the ex ante individual rationality constraints $\left(I R_{i}^{x a}\right)$, the optimal menu of option contracts is given by $\left(\mathbf{F}^{x a}, \mathbf{R}^{x a}\right) \equiv$ $\left(\left(F_{1}^{x a}, R_{1}^{x a}\right), \ldots,\left(F_{n}^{x a}, R_{n}^{x a}\right)\right)$.

Hence, in contrast to the case with withdrawal rights, the optimal menu without withdrawal rights screens sequentially in that it offers different option contracts to different ex ante types. Moreover, it violates all ex post individual rationality constraints $\left(I R_{i}^{x p}\right)$ because the fact that $R_{i}^{x a}<R_{i+1}^{x a}$ implies that:

$$
0<F_{n}^{x a} \leq \ldots \leq F_{1}^{x a}
$$

This ordering also reveals the intuition why, in the absence of withdrawal rights, offering the optimal static menu from Proposition 1 is not optimal. Observe that a reduction of the exercise price increases the buyer's "ex post information rent" which amounts to his total utility net of the up-front payment. The reduction raises, moreover, the surplus as long as the price still remains above costs. Therefore, if all buyer types were offered the option contract $(0, \bar{R})$ from the optimal static menu, the seller could reduce the exercise price for type 1 , thereby increasing his ex post information rent, and at the same time impose an appropriate up-front fee that exactly extracts type 1's gain 
in ex post information rent. Under first order stochastic dominance, such a modification is incentive compatible because any other type is less optimistic about his valuation than type 1 so that such a type's gain in ex post information rent in response to a price decrease is smaller than type 1's.

Conversely, one may ask why, with withdrawal rights, it is not optimal to screen sequentially. First note that the seller can, in principle, induce the same buying behavior as under the sequential menu $\left(\mathbf{F}^{x a}, \mathbf{R}^{x a}\right)$, but to satisfy ex post individual rationality, this requires her to decrease all up-front fees $F_{i}$ by the fixed amount $F_{1}^{x a}$. Therefore, it is feasible to sequentially screen the buyer also in the presence of withdrawal rights, but as we have shown, it is not optimal to do so. In this sense, Proposition 1 is an optimality result rather than an implementation result. The reason why sequential screening is not optimal is implicit in the previous paragraph. Withdrawal rights prevent the seller from using the up-front fee to extract the additional surplus created by sequential screening.

\subsubsection{Welfare effects}

In this section, we explore the welfare effects of introducing withdrawal rights. Our approach compares the parties' utilities and aggregate surplus under the optimal contracts with and without such rights.

We begin with the straightforward observation that the seller is (weakly) worse off when withdrawal rights are introduced. This follows simply from the fact that with withdrawal rights she faces more constraints. Even though straightforward, this observation clarifies that, in a sequential screening setup, the seller has no incentive to offer a withdrawal right voluntarily. Hence, if, as in the context of the EU regulation, society considers withdrawal rights desirable, then the incentives of the seller are misaligned with society so that these rights have to be imposed upon the seller in the form of explicit regulation.

In contrast, the effect on the aggregate surplus and on the buyer's expected utility is, in general, ambiguous. Both with and without withdrawal rights, exercise prices are inefficiently distorted away from marginal costs and the overall welfare effect depends on the magnitude of these distortions. To see this more formally, the difference in aggregate 

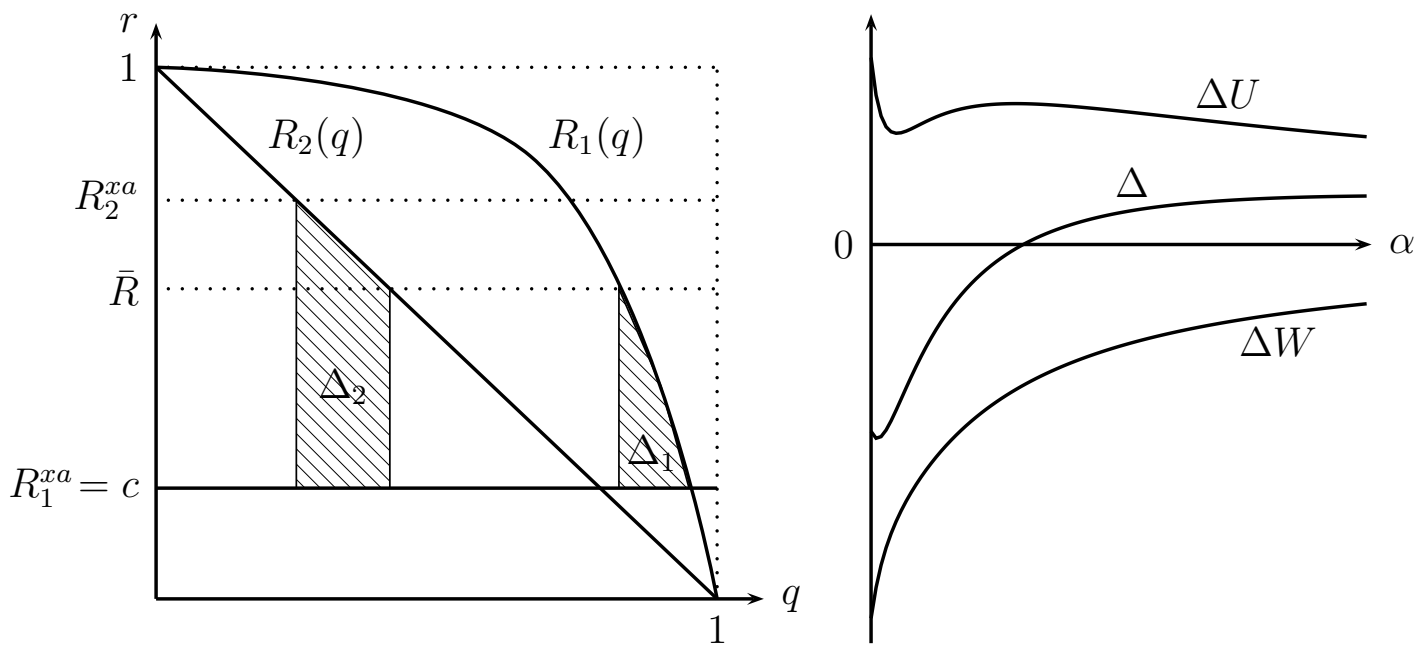

Figure 1: Dead weight loss and welfare effects of withdrawal rights with two types.

surplus conditional on an ex ante type $i$ is

$$
\Delta_{i} \equiv \int_{\bar{R}}^{1} \theta-c d G_{i}(\theta)-\int_{R_{i}^{x a}}^{1} \theta-c d G_{i}(\theta)=\int_{\bar{R}}^{R_{i}^{x a}} \theta-c d G_{i}(\theta)
$$

so that the regulation changes the aggregate surplus by $\Delta=\sum_{i} p_{i} \Delta_{i}$. The sign of $\Delta_{i}$ depends on the ordering of $R_{i}^{x a}$ and $\bar{R}$. Only for type 1 this ordering is unambiguous, since $R_{1}^{x a}=c<\bar{R}$. But for $i>1$, it depends on the details of the model whether $R_{i}^{x a}$ is smaller or larger than $\bar{R}$.

The left panel in Figure 1 illustrates the welfare effects with two ex ante types. We may interpret the downward sloping curve $R_{i}(q)=G_{i}^{-1}(1-q)$ as a usual (inverse) demand function where $q$ denotes the ex ante probability of trade under $G_{i}$. When $G_{1}$ first order stochastically dominates $G_{2}$, the curve $R_{1}(q)$ lies above the curve $R_{2}(q)$. Conditional on type 1 , withdrawal rights cause the deadweight loss given by area $\left|\Delta_{1}\right|$ due to the price increase from $R_{1}^{x a}=c$ to $\bar{R}>c$. The graph depicts the case in which $R_{2}^{x a}>\bar{R}$ so that, conditional on ex ante type 2, withdrawal rights induce a welfare gain of $\Delta_{2}$. The regulation is welfare enhancing whenever $p_{2} \Delta_{2} \geq p_{1}\left|\Delta_{1}\right|$.

The welfare comparison is clear-cut for the extreme case that there is no private ex ante information. Absent ex ante private information, it is well-known that without withdrawal rights, the seller can extract all gains of trade, despite the buyer's ex post private information (see Harris and Raviv, 1979). Consequently, allocations are efficient. 
In contrast, Sappington (1983) shows that if the seller has to respect the ex post individual rationality constraints implied by withdrawal rights, then full rent extraction is not possible. As a result, allocations are distorted. Hence, when there is little ex ante private information, withdrawal rights are welfare reducing.

To shed light on less extreme cases, the right panel in Figure 1 illustrates the change in welfare $(\Delta)$, profits $(\Delta W)$, and buyer rents $(\Delta U)$ for the specification

$$
p_{1}=p_{2}=1 / 2, \quad c=1 / 4, \quad G_{2}(\theta)=\theta, \quad G_{1}(\theta)=\theta^{1+\alpha}, \quad \alpha \geq 0 .
$$

For $\alpha=0$, we have $G_{1}=G_{2}$ so that there is no relevant ex ante private information. Hence, the previous paragraph explains why the graph starts with $\Delta$ and $\Delta W$ negative and $\Delta U$ positive. For $\alpha \approx \infty$, ex ante type 1 is virtually ensured to have valuation $\theta=1$ so that for any price $\bar{R}<1$ he always buys. As a result, withdrawal rights do not affect the surplus from type 1 too negatively $\left(\Delta_{1} \approx 0\right)$. In this case, the buyer's gain from the regulation outweighs the seller's loss, and it is therefore socially beneficial $(\Delta>0)$. The non-monotone comparative statics with respect to the buyer's rents, $\Delta U$, and aggregate surplus, $\Delta$, demonstrate that already with two ex ante types the welfare effects depend in a non-trivial way on the details of the model.

\subsection{Bonds and differences in outside options}

In the analysis so far, we assumed that, by withdrawing from the contract, the buyer can obtain his outside option of zero and therefore avoid any losses ex post. In other words, withdrawal allows the buyer to reclaim any payment he might have made ex ante. As a result, the seller cannot require the buyer to post a non-refundable bond when the contract is signed. This assumption is in line with Section 49 of the EU directive, which states: "In the event that the consumer withdraws from the contract, the trader should reimburse all payments received from the consumer, including those covering the expenses borne by the trader to deliver goods to the consumer".

In this subsection, we extend our results to sequential screening environments in which the agent has an ex post withdrawal right but can post positive bonds. We first show that such environments are equivalent to a setting in which the agent's ex ante outside option exceeds his ex post outside option. Subsequently, we show that our main result 
remains true as long as the bond the agent can post is below a certain, strictly positive bound. As argued in the introduction, in practice, such bounds exist for legal reasons or because the agent is cash-constrained.

We start by assuming that the buyer has a (normalized) ex ante outside option of zero and an ex post outside option equal to $-B<0$. Thus, a menu of option contracts is ex post individually rational if and only if $V_{i}(\theta) \geq-B$ for all $i, \theta$, which by (8) is equivalent to

$$
F_{i} \leq B \quad \text { for all } i \in I
$$

In contrast, the ex ante individual rationality constraint $\left(I R_{i}^{x a}\right)$ remains unaffected.

Alternatively, we can interpret the constraint (15) as representing a situation in which the buyer does have an ex post outside option of zero, but in period 1 the seller can demand an up-front payment up to the amount $B$, which she retains when the buyer withdraws in period 2. Effectively, it is as if the buyer pays a non-refundable bond $F_{i}$ in period 1 and decides in period 2 whether to consume at the exercise price or not, knowing that the payment $F_{i}$ is sunk.

We now argue that our result that the static contract is optimal still holds when $B$ is strictly positive but not too large:

\section{Proposition 2 Let}

$$
B^{x p} \equiv \min _{i} \int_{\bar{R}}^{1} 1-G_{i}(\theta) d \theta
$$

If the maximal bond $B$ is smaller than $B^{x p}$, or, equivalently, if the buyer's ex post outside option is larger than $-B^{x p}$, then the static menu $\left(\mathbf{F}^{\mathbf{x p}}, \mathbf{R}^{\mathbf{x p}}\right)$ with $\left(F_{i}^{x p}, R_{i}^{x p}\right)=(B, \bar{R})$ for all $i \in I$ is optimal.

Because $B^{x p}>0$, our result that sequential screening is not beneficial with ex post individual rationality constraints is robust. ${ }^{22}$ It extends to cases in which posting a limited bond is possible, or in which the seller's ex post outside option is not too small.

To see Proposition 2, note first that if we continue to disregard the ex ante individual rationality constraint $\left(I R_{i}^{x a}\right)$ and solve problem $\mathcal{P}^{o}$ but with the adapted ex post individual rationality constraint $(15)$ instead of $\left(I R_{i}^{x p}\right)$, then the arguments leading to Proposition

\footnotetext{
${ }^{22}$ Note that the bound $B^{x p}$ does not converge to zero as the number of ex ante types $n$ increases.
} 
1 imply that the solution corresponds again to a static contract with the single price $\bar{R}$, but now with the up-front fee $F_{i}=B$. For this solution, it follows that the ex ante utility of type $i$ is

$$
U_{i i}=-B+\int_{\bar{R}}^{1} 1-G_{i}(\theta) d \theta .
$$

Hence, for $B \leq B^{x p}$, the solution satisfies automatically the ex ante individual rationality constraint $\left(I R_{i}^{x a}\right)$ for any $i$, implying Proposition 2 .

Taking the opposite approach and solving the model with the ex ante individual rationality constraint $\left(I R_{i}^{x a}\right)$ while disregarding the ex post individual rationality constraint (15) yields the solution of Lemma 2 (under the appropriate distributional assumptions of the lemma). Recall from (14) that the ex ante type 1 pays the largest up-front fee, and with (12) and (13), we obtain

$$
F_{1}^{x a}=\sum_{i=1}^{n} \int_{\theta_{i}^{x a}}^{\theta_{i+i}^{x a}} 1-G_{i}(\theta) d \theta \equiv B^{x a},
$$

where $\theta_{n+1}^{x a} \equiv 1$. Since $F_{1}^{x a} \geq F_{i}^{x a}$ for all $i \in I$, the solution satisfies the neglected ex post individual rationality constraint (15) whenever $B \geq B^{x a}$.

It follows that as we vary the maximal bond $B$, we obtain the sequential screening models with ex ante and ex post individual rationality constraints as two extremes: the model with ex ante constraints for $B \geq B^{x a}$ and the model with ex post constraints for $B \leq B^{x p}$.

\subsection{Costly returns}

Until now we abstracted from any costs of returning the good. In practice, however, returning goods involves at least some transportation costs. The EU directive allows these costs to be borne by the buyer. ${ }^{23}$ In this subsection, we show that costly returns have a similar effect as introducing differences between the buyer's ex ante and ex post outside option as discussed in the previous subsection. In particular, the optimal contract

\footnotetext{
${ }^{23}$ Article $6(\mathrm{i})$ of the directive states "the consumer will have to bear the cost of returning the goods in case of withdrawal". The implementation of the earlier directive 97/7/EC differed among member states. Most member states allowed that consumers pay for returning the good, but, for instance, Germany required that the seller pays for returns for any goods that were sold in excess of 40 Euros.
} 
remains static if the return costs are small relative to the expected surplus generated under the optimal static contract.

More specifically, suppose the agent incurs some cost $k \geq 0$ when he returns the good to the seller. With return costs, there are now three options concerning the good's allocation, each leading to a different aggregate surplus:

1. The good is sent to the buyer with some ex post valuation $\theta$, who keeps it and thereby generates the aggregate surplus $\theta-c$.

2. The good is sent to the buyer, but he returns it and thereby generates the surplus $-k$.

3. The good is not sent to the buyer at all, which generates a surplus of 0 .

We start by deriving the optimal option menu under the assumption that the seller always sends the good to the buyer for inspection. Let

$$
\begin{aligned}
\bar{R}^{k} & \equiv \arg \max _{R}(1-\bar{G}(R-k))(R-c), \\
K & \equiv \min _{i \in I} \int_{\bar{R}^{k}-k}^{1} 1-G_{i}(\theta) d \theta .
\end{aligned}
$$

The next lemma states that if return costs are smaller than $K$, then it is optimal for the seller to simply offer the good at the price $\bar{R}^{k}$ :

Lemma 3 Suppose return costs $k$ are smaller than $K$, and that it is optimal for the seller to send the good to all ex ante buyer types. Then an optimal menu of option contracts consists of a single contract only: $\left(F_{i}, R_{i}\right)=\left(0, \bar{R}^{k}\right)$ for all $i \in I$.

To see the result, consider a buyer, who after learning his ex post type $\theta$ contemplates exercising his option to buy the good. If he decides not to exercise his option, he now has to incur the return cost $k$. Hence, under an option contract $\left(F_{j}, R_{j}\right)$, buyer type $i$ keeps the good if $\theta \geq R_{j}-k$, implying the ex post utility

$$
V_{i}^{k}(\theta)= \begin{cases}-F_{j}+\left(\theta-R_{j}\right) & \text { if } \theta \geq R_{j}-k \\ -F_{j}-k & \text { otherwise, }\end{cases}
$$

and the ex ante utility

$$
U_{j i}^{k}=-F_{j}+\int_{R_{j}-k}^{1} \theta-R_{j} d G_{i}(\theta)-G_{i}\left(R_{j}-k\right) k .
$$


Because the buyer incurs the return cost $k$ when returning the good, the ex post individual rationality constraints now only guarantee that the buyer's ex post utility does not fall below $-k$ : $V_{i}^{k}(\theta) \geq-k$ for all $i, \theta$. As before, this is equivalent to $F_{i} \leq 0$ for all $i$. Hence, the constraint $\left(I R_{i}^{x p}\right)$ remains unchanged. Moreover, the definitions of incentive compatibility $\left(I C_{i j}\right)$ and ex ante individual rationality $\left(I R_{i}^{x a}\right)$ also remain the same. However, in contrast to the model without return costs, ex post individual rationality does no longer imply ex ante individual rationality because the buyer may end up with the negative utility $-k$ associated with returning the good ex post. Hence, as in the previous subsection, return costs create a wedge between the ex post and ex ante individual rationality constraints. For this reason, also with costly returns, we have to consider explicitly the ex ante individual rationality constraint $\left(I R_{i}^{x a}\right)$.

Given a buyer type $i$, an incentive compatible menu $(\mathbf{F}, \mathbf{R})$ generates the surplus

$$
S_{i}^{k}=\int_{R_{i}-k}^{1} \theta-c d G_{i}(\theta)-G_{i}\left(R_{i}-k\right) k
$$

so that the seller's conditional expected payoff from a buyer type $i$ is $W_{i}^{k}=S_{i}^{k}-U_{i i}^{k}$.

Consequently, for the case that the good is always sent to the buyer, we obtain the optimal menu of option contracts with return costs as a solution to problem $\mathcal{P}^{o}$ but with the adjusted payoff functions $V_{i}^{k}, U_{j i}^{k}, W_{i}^{k}$ and the explicit inclusion of the additional constraint $\left(I R_{i}^{x a}\right)$. Yet, if we ignore $\left(I R_{i}^{x a}\right)$, then Proposition 1 directly implies that the solution is given by the static menu $\left(F_{i}, R_{i}\right)=\left(0, \bar{R}^{k}\right)$. We now show that if $k \leq K$, then this solution automatically satisfies $\left(I R_{i}^{x a}\right)$ so that the static menu is indeed also optimal with return costs.

To see this observe that the option contract $\left(F_{i}, R_{i}\right)=\left(0, \bar{R}^{k}\right)$ yields buyer type $i$ a utility of

$$
U_{i i}=\int_{\bar{R}^{k}-k}^{1} \theta-\bar{R}^{k} d G_{i}(\theta)-G_{i}\left(\bar{R}^{k}-k\right) k=\int_{\bar{R}^{k}-k}^{1} 1-G_{i}(\theta) d \theta-k,
$$

where the second equality follows from integration by parts. Hence, if $k \leq K$, then $U_{i i} \geq 0$ so that the static menu is ex ante individually rational. This establishes Lemma 3.

Lemma 3 derives the optimal contract under the assumption that the seller sends the good to the buyer for each ex ante type. Because returning the good is costly, the seller may, however, find it suboptimal to send the good to ex ante types who are likely to 
return the good. Instead, she may prefer to "screen ex ante types by participation" and not send the good to all ex ante types.

To study this possibility, we introduce the following notation. Given a subset $J \subseteq I$ of ex ante buyer types, denote by $\bar{G}_{J} \equiv \sum_{j \in J} p_{j} G_{j}$ the average distribution over types in $J$. Moreover, let

$$
\bar{R}_{J}=\arg \max _{R}\left(1-\bar{G}_{J}(R-k)\right)(R-c) .
$$

We now state the problem of the seller who wants to send the good only to ex ante types $j$ in some set $J \subset I$. In this case, the seller needs to induce the types $i \in I \backslash J$ not to participate. Hence, the seller must ensure that these types do not obtain a positive utility from choosing the contract $\left(F_{j}, R_{j}\right)$ of some ex ante type $j \in J$ who does receive the good. This yields the additional "screening by participation" constraint

$$
U_{j i}^{k} \leq 0 \quad \text { for all } i \in I \backslash J, j \in J \text {. }
$$

An optimal menu of option contracts under which the good is sent only to the ex ante types in $J$ is a solution to the following program:

$$
\mathcal{P}^{J}: \quad \max _{(\mathbf{F}, \mathbf{R})} \sum_{j \in J} p_{j} W_{j}^{k} \quad \text { s.t. } \quad\left(I C_{i j}\right),\left(I R_{i}^{x p}\right),\left(I R_{i}^{x a}\right),\left(I C_{J}\right) .
$$

We finally show that when costs satisfy an analogous condition as the one in Lemma 3 , then an optimal menu of option contracts that screens by participation is still static in the sense that it does not screen between the ex ante types who do receive the good.

Proposition 3 Let

$$
K^{J} \equiv \min _{j \in J^{*}} \int_{\bar{R}_{J^{*}-k}}^{1} 1-G_{j}(\theta) d \theta
$$

If return costs $k$ are smaller than $K^{J}$, and it is optimal for the seller to send the good to ex ante types in $J^{*}$, then the static menu $\left(\mathbf{F}^{\mathbf{k}}, \mathbf{R}^{\mathbf{k}}\right)$ with $\left(F_{j}^{k}, R_{j}^{k}\right)=\left(0, \bar{R}_{J^{*}}\right)$ for all $j \in J^{*}$ is optimal.

\section{General contracts}

In the previous sections, we considered deterministic selling schedules. We now allow the seller to choose stochastic schedules

$$
x_{i}(\theta) \in[0,1]
$$


The main question of this section is when the optimal contract, within the set of all contracts, is deterministic. In standard screening problems, the optimality of deterministic contracts is typically ensured by regularity conditions. It should therefore not be too surprising that also in our setting we need to impose additional distributional assumptions. In what follows, we first of all impose the usual smoothness assumptions that the probability density $g_{i}(\theta)=G_{i}^{\prime}(\theta)$ exists, is differentiable and strictly positive for all $\theta \in[0,1]$. Our key regularity condition is:

Condition $\mathbf{R}$ The cross hazard rate between the types $i$ and $j$ and the hazard rate of type $i$, defined as

$$
h_{i, j}(\theta) \equiv \frac{1-G_{i}(\theta)}{g_{j}(\theta)}, \quad \text { and } \quad h_{i}(\theta) \equiv h_{i, i}(\theta),
$$

are decreasing in $\theta$ for all $i, j .{ }^{24,25}$

Before stating the main result of this section, recall from the end of Subsection 2.1 that the optimal static contract displays the selling schedule

$$
\overline{\mathbf{x}} \equiv\left(x_{1}(\theta), \ldots, x_{n}(\theta)\right), \quad x_{i}(\theta) \equiv \bar{x}(\theta)=\mathbf{1}_{[\bar{R}, 1]}(\theta) \quad \text { for all } i \in I
$$

where 1 denotes the indicator function.

Theorem 1 If condition $R$ holds, the seller's problem $\mathcal{P}$ has a deterministic solution. Moreover, the optimal selling schedule is given by $\overline{\mathbf{x}}$.

The second part of the theorem simply re-states Proposition 1 that the optimal deterministic contract corresponds to the optimal static contract and does not depend on the ex ante type. Therefore, the interesting question in this section is why the optimal deterministic contract is indeed a solution to $\mathcal{P}$.

\footnotetext{
${ }^{24}$ As can be seen from (11), cross-hazard rates are an essential part of the modified hazard rate, informativeness measure, or impulse response function and, hence, play a prominent role in the literature on dynamic mechanism design. We are however not aware that their role has been noted before.

${ }^{25}$ Because $h_{i j}(\theta)>0$ for all $\theta<1$ and $h_{i j}(1)=0$, a cross hazard rate is always decreasing close to $\theta=1$. Condition $\mathrm{R}$, therefore, requires it to be decreasing on the entire interval $\theta \in[0,1)$. A sufficient condition to obtain Condition $\mathrm{R}$ is that densities $g_{i}$ are increasing, or, equivalently, that the cumulative distributions $G_{i}$ are convex. Condition $\mathrm{R}$ is therefore satisfied for large families of distributions. A concrete example is $G_{i}(\theta)=\theta^{a_{i}}$ with $1 \geq a_{1}>\ldots>a_{n}$.
} 
In standard screening problems, the optimality of deterministic contracts obtains when the so-called "local Mirlees" or "first order" approach is valid (see Strausz 2006). This approach considers a relaxed problem where only the local incentive compatibility constraints are imposed but all global constraints are ignored. Regularity conditions then guarantee that the solution to the relaxed problem is a solution to the original problem and, moreover, that the solution is deterministic. Even though our regularity condition $\mathrm{R}$ displays some similarity to those of standard screening problems, the first order approach turns out to fail in our setting. ${ }^{26}$ The main challenge is, therefore, to identify a set of (global) incentive constraints, different from the local ones, which does allow us to derive the optimal contract.

In the first step, we follow the familiar procedure and make the seller's problem more amenable by eliminating transfers from the problem. As is standard, incentive compatibility in the second period is equivalent to (i) monotonicity of the selling schedule,

$$
x_{i}(\theta) \text { is increasing in } \theta \text { for all } i \in I \text {; }
$$

and (ii) "revenue equivalence", which means that the buyer's utility is determined by the selling schedule up to his utility at the lowest valuation, $v_{i}(0)$. We can use "revenue equivalence" to eliminate transfers and obtain the seller's problem as a choice problem over the selling schedule $\mathbf{x}$ and the vector $\mathbf{v}=\left(v_{i}(0)\right)_{i \in I}$. Formally, the first period incentive compatibility and the ex post participation constraints can respectively be re-written as

$$
\begin{gathered}
\int_{0}^{1}\left[x_{i}(\theta)-x_{j}(\theta)\right]\left[1-G_{i}(\theta)\right] d \theta+v_{i}(0)-v_{j}(0) \geq 0, \\
v_{i}(0) \geq 0
\end{gathered}
$$

and the seller's objective becomes

$$
w(\mathbf{x}, \mathbf{v})=\sum_{i \in I} p_{i} \int_{0}^{1}\left[\theta-c-h_{i}(\theta)\right] x_{i}(\theta) d G_{i}(\theta)-p_{i} v_{i}(0) .
$$

The following lemma summarizes.

Lemma 4 The seller's problem can be equivalently written as follows:

$$
\mathcal{P}: \quad \max _{\mathbf{x}, \mathbf{v}} w(\mathbf{x}, \mathbf{v}) \quad \text { s.t. } \quad\left(M O N_{i}\right),\left(I C_{i j}^{\mathbf{v}}\right),\left(I R_{i}\right) \quad \text { for all } i, j \in I
$$

\footnotetext{
${ }^{26}$ Battaglini and Lamba (2014) argue that the first order approach "often" fails in dynamic screening problems.
} 
Our approach to solving problem $\mathcal{P}$ is to first solve an auxiliary problem where we set $v_{i}(0)$ exogenously equal to zero. We refer to this auxiliary problem as $\mathcal{P}^{0}{ }^{27}$

$$
\mathcal{P}^{0}: \quad \max _{\mathbf{x}} w(\mathbf{x}, \mathbf{0}) \quad \text { s.t. } \quad\left(M O N_{i}\right),\left(I C_{i j}^{0}\right) \quad \text { for all } i, j \in I, i \neq j .
$$

We next show that the optimal deterministic selling schedule $\overline{\mathbf{x}}$ is a solution to $\mathcal{P}^{0}$. In a second step, we then verify that it is indeed optimal to set $v_{i}(0)$ equal to zero.

To solve $\mathcal{P}^{0}$, we consider a relaxed problem where we ignore the monotonicity constraints $\left(M O N_{i}\right)$ and consider only a subset of incentive constraints. We identify an incentive constraint $I C_{i j}$ with its respective index $(i, j)$. For a subset $C \subseteq\left\{(i, j) \in I^{2} \mid i \neq j\right\}$, we denote by $\mathcal{R}^{0}(C)$ the relaxed problem where only the constraints in $C$ are considered:

$$
\mathcal{R}^{0}(C): \quad \max _{\mathbf{x}} w(\mathbf{x}, \mathbf{0}) \quad \text { s.t. } \quad\left(I C_{i j}^{0}\right) \text { for all }(i, j) \in C .
$$

The next lemma shows that in order to verify that the static solution $\overline{\mathbf{x}}$ solves problem $\mathcal{P}^{0}$, it is sufficient to find a set $C$ so that $\overline{\mathbf{x}}$ solves $\mathcal{R}^{0}(C)$.

Lemma 5 If there is a set $C$ so that $\overline{\mathbf{x}}$ is a solution to $\mathcal{R}^{0}(C)$, then $\overline{\mathbf{x}}$ is a solution to $\mathcal{P}^{0}$.

The lemma holds simply, because $\overline{\mathbf{x}}$ trivially satisfies the monotonicity and the remaining incentive constraints in $\mathcal{P}^{0}$ that were neglected in $\mathcal{R}^{0}(C)$.

To find a set $C$ so that $\overline{\mathbf{x}}$ solves $\mathcal{R}^{0}(C)$,we will work with the Kuhn-Tucker theorem for function spaces. Following Luenberger (1969, p.220), a selling schedule $\mathbf{x}$ solves $\mathcal{R}^{0}(C)$ if and only if

(i) there are multipliers $\lambda_{i j} \leq 0$ associated to constraint $I C_{i j}^{0}$, and

(ii) $\mathbf{x}$ maximizes the Lagrangian

$$
\begin{aligned}
\mathcal{L}^{0}(C) & =\sum_{k \in I} \int_{0}^{1} p_{k}\left[\theta-c-h_{k}(\theta)\right] x_{k}(\theta) g_{k}(\theta) d \theta-\sum_{(i, j) \in C} \lambda_{i j} \int_{0}^{1}\left[x_{i}(\theta)-x_{j}(\theta)\right]\left[1-G_{i}(\theta)\right] d \theta \\
& =\sum_{k \in I} \int_{0}^{1}\left\{p_{k}\left[\theta-c-h_{k}(\theta)\right]-\sum_{j:(k, j) \in C} \lambda_{k j} h_{k}(\theta)+\sum_{i:(i, k) \in C} \lambda_{i k} h_{i, k}(\theta)\right\} x_{k}(\theta) g_{k}(\theta) d \theta,
\end{aligned}
$$

(iii) and, moreover, $\lambda_{i j}=0$ only if the inequality in $I C_{i j}^{0}$ is strict.

\footnotetext{
${ }^{27}$ Notice that because $v_{i}(0)=0$ for all $i \in I,\left(I R_{i}\right)$ is redundant in $\mathcal{P}^{0}$. Moreover, we denote by $I C_{i j}^{0}$ the constraint $I C_{i j}^{\mathbf{v}}$ for $v_{i}(0)=0$ for all $i \in I$.
} 
For a given set $C$, let us spell out when the optimal deterministic schedule $\overline{\mathbf{x}}$ satisfies the three conditions. Since $\overline{\mathbf{x}}$ trivially satisfies $I C_{i j}^{0}$ with equality, the third condition is redundant. Moreover, by point-wise maximization, a selling schedule maximizes the Lagrangian $\mathcal{L}^{0}(C)$ if $x_{k}(\theta)$ is set to 1 whenever the expression in curly brackets under the integral,

$$
\Psi_{k}(\theta, C, \lambda) \equiv p_{k}\left[\theta-c-h_{k}(\theta)\right]-\sum_{j:(k, j) \in C} \lambda_{k j} h_{k}(\theta)+\sum_{i:(i, k) \in C} \lambda_{i k} h_{i, k}(\theta)
$$

is positive, and $x_{k}(\theta)$ is set to 0 otherwise. ${ }^{28}$ Therefore, a sufficient condition for $\overline{\mathbf{x}}$ to maximize the Lagrangian is that $\Psi_{k}(\bar{R}, C, \lambda)=0$ and $\Psi_{k}(\theta, C, \lambda)$ is increasing in $\theta$ for all $k \in I$. We summarize this observation in the following lemma.

Lemma 6 The optimal deterministic schedule $\overline{\mathbf{x}}$ is a solution to $\mathcal{R}^{0}(C)$ if for all $(i, j) \in C$ there is a $\lambda_{i j}$ so that

$$
\begin{gathered}
\lambda_{i j} \leq 0, \\
\Psi_{k}(\bar{R}, C, \lambda)=0, \quad \Psi_{k}(\theta, C, \lambda) \text { is increasing in } \theta \quad \forall k \in I .
\end{gathered}
$$

We are now looking for a set $C$ so that $\left(K T_{1}\right)$ and $\left(K T_{2}\right)$ are satisfied. We begin by introducing notation. For each $i$, let $\theta_{i}$ be implicitly given by

$$
\theta_{i}=c+h_{i}\left(\theta_{i}\right)
$$

Because, by condition $\mathrm{R}$, the hazard rate is decreasing, $h_{i}(1)=0$, and $c \in[0,1), \theta_{i}$ is unique, exists, and lies in between $c$ and 1 . Observe that $\theta_{i}$ corresponds to the optimal monopoly price the seller would charge if he knew the buyer's ex ante type is $i$. In other words, if the buyer's ex ante type is publicly known, the seller optimally offers the schedule $x_{i}(\theta)=\mathbf{1}_{\left[\theta_{i}, 1\right]}$ to the buyer.

We now label the ex ante types according to the order of monopoly prices.

$$
c<\theta_{n} \leq \ldots \leq \theta_{i} \leq \ldots \leq \theta_{1}<1
$$

We choose this ordering because it corresponds to the usual ordering of types in a static screening problem with single crossing. To see this note that if the seller offered the selling schedule that is optimal with publicly known ex ante types, then types with

\footnotetext{
${ }^{28}$ The argument $\lambda$ in $\Psi_{k}$ represents the vector $\left\{\lambda_{i j}\right\}_{(i, j) \in C}$.
} 
higher prices, and hence lower indices $i$, "envy" the allocations of types with lower prices and hence higher indices $j>i$.

With this ordering, the familiar Mirrlees approach suggests to consider the set of local constraints $I C_{i, i+1}^{0}$ which ensure that no type has incentives to mimic a neighbouring type. We will now argue that for the set of Mirrleesian constraints, the monotonicity requirement in $\left(K T_{2}\right)$ cannot be established straightforwardly. Indeed, consider the case with three types $n=3$. When we only consider the local constraints $I C_{12}^{0}$ and $I C_{23}^{0}$ so that $C=\{(1,2),(2,3)\}$, then we obtain for type $k=2$ :

$$
\Psi_{2}(\theta, C, \lambda)=p_{2}[\theta-c]-\left[p_{2}+\lambda_{23}\right] h_{2}(\theta)+\lambda_{12} h_{12}(\theta)
$$

To satisfy $\left(K T_{2}\right), \Psi_{2}(\theta, C, \lambda)$ needs to be increasing in $\theta$. Because condition $\mathrm{R}$ states that the (cross) hazard rates are decreasing, $p_{2}+\lambda_{23} \geq 0$ and $\lambda_{12} \leq 0$ is a sufficient condition for concluding that $\Psi_{2}(\theta, C, \lambda)$ is indeed increasing in $\theta$. Whereas the latter inequality is in line with $\left(K T_{1}\right)$, the former holds only if $\lambda_{23}$ is not too negative, but it is not clear whether this is the case, especially since $\left(K T_{1}\right)$ requires $\lambda_{23}$ to be negative.

In general, we encounter this problem whenever the set of constraints contains $I C_{k j}^{0}$ and $I C_{i k}^{0}$ at the same time, or, in other words, whenever type $k$ is both an "envying" and an "envied" type. This suggests to consider sets of constraints in which an "envying" type is not an "envied" type. We call such a set directed:

Definition 1 A set $C$ is called directed if for all $i$ :

$$
(i, j) \in C \text { for some } j \quad \Rightarrow \quad(k, i) \notin C \text { for all } k \text {. }
$$

The next lemma shows that for a directed set, the functions $\Psi_{k}$ are strictly increasing provided they have a root in the interval $[c, 1]$.

Lemma 7 Let $C$ be directed and $\lambda_{i j} \leq 0$ for all $(i, j) \in C$. If there is a solution $\hat{\theta} \in[c, 1]$ to $\Psi_{k}(\hat{\theta}, C, \lambda)=0$, then $\Psi_{k}(\theta, C, \lambda)$ is strictly increasing in $\theta$.

Now observe that $\bar{R} \in[c, 1]$. Hence, Lemma 6 and 7 combined imply

Lemma 8 If $C$ is directed, then $\overline{\mathbf{x}}$ is a solution to $\mathcal{R}^{0}(C)$ if there exist $\lambda_{i j}$ so that

$$
\lambda_{i j} \leq 0 \quad \forall(i, j) \in C, \quad \text { and } \quad \Psi_{k}(\bar{R}, C, \lambda)=0 \quad \forall k \in I .
$$


We now show that, for any problem $\mathcal{P}^{0}$, a directed set of constraints which satisfies (18) exists. ${ }^{29}$ As it turns out, the relevant set of constraints depends on how $\bar{R}$ is ordered relative to the values $\theta_{k}$ defined in (16).

To understand this, consider a set of directed constraints $C$ which contains a constraint $(i, j) \in C$ that involves an "envying" type $i$ with $\theta_{i}<\bar{R}$. We now argue that in this case, $C$ violates (18), and $\overline{\mathbf{x}}$ is not a solution to $\mathcal{R}^{0}(C)$, because rather than offering type $i$ the schedule $\bar{x}(\theta)=\mathbf{1}_{[\bar{R}, 1]}(\theta)$, the seller would improve by offering $\tilde{x}_{i}(\theta)=\mathbf{1}_{\left[\theta_{i}, 1\right]}(\theta)$ instead. In fact, by definition of $\theta_{i}$, this would improve the objective; further, it would relax all incentive constraints $I C_{i j}^{0}$ since $\theta_{i}<\bar{R}$; finally, because $C$ is directed and type $i$ is envying, the modification would leave all other incentive constraints unaffected. Therefore, in order not to be able to improve upon the optimal deterministic schedule $\overline{\mathbf{x}}$, any type $i$ with $\theta_{i}<\bar{R}$ should be an "envied" type. By a similar argument, any type $i$ with $\theta_{i} \geq \bar{R}$ should be an "envying" type.

The previous discussion suggests to consider a set which contains any constraint $I C_{i j}^{0}$ if $\theta_{i} \geq \bar{R}$ and $\theta_{j}<\bar{R}$ :

$$
C^{*} \equiv I^{-} \times I^{+}
$$

where

$$
I^{-} \equiv\left\{i \in I \mid \theta_{i} \geq \bar{R}\right\}, \quad I^{+} \equiv\left\{j \in I \mid \theta_{j}<\bar{R}\right\}
$$

Clearly, $C^{*}$ is directed. Moreover, we show in the appendix that $\bar{R} \in\left[\theta_{n}, \theta_{1}\right]$, and, therefore, $C^{*}$ is non-empty.

Now, let $L=\left|I^{-}\right| \cdot\left|I^{+}\right|$be the number of constraints in $C^{*}$. Then the condition in the right part of (18),

$$
\Psi_{k}\left(\bar{R}, C^{*}, \lambda\right)=0 \quad \text { for all } k \in I,
$$

corresponds to a system of $n$ linear equations in the $L$ unknowns $\lambda_{i j}$. Hence, $C^{*}$ satisfies (18) if this system has a non-positive solution. Using Farkas' lemma, we now prove that this is always the case. This is the central step towards establishing our result.

\footnotetext{
${ }^{29}$ In our working paper version (Krähmer and Strausz 2012) we present a constructive but lengthy procedure by which to identify the exact relevant constraints. Here we provide instead a much shorter albeit indirect proof.
} 
Lemma $9 C^{*}$ satisfies (18).

According to Lemma 8, Lemma 9 implies that the optimal deterministic schedule $\overline{\mathbf{x}}$ solves problem $\mathcal{R}^{0}\left(C^{*}\right)$, and thus, by Lemma 5 , it also solves problem $\mathcal{P}^{0}$. In problem $\mathcal{P}^{0}$, we set $v_{i}(0)$ exogenously to zero. We now consider the original problem $\mathcal{P}$, in which $v_{i}(0)$ is a choice variable of the seller. To do so, we consider the relaxed problem where we ignore the monotonicity constraints and consider only the incentive constraints in the set $C^{*}=I^{-} \times I^{+}$:

$\mathcal{R}: \quad \max _{\mathbf{x}, \mathbf{v}} w(\mathbf{x}, \mathbf{v}) \quad$ s.t. $\quad\left(I C_{i j}^{\mathbf{v}}\right),\left(I R_{k}\right) \quad$ for all $(i, j) \in C^{*}, k \in I$.

We have:

Proposition 4 Let condition $R$ hold. Then the optimal deterministic contract $(\overline{\mathbf{x}}, \overline{\mathbf{v}})$, where $\bar{v}_{i}(0)=0$ for all $i \in I$, is a solution to problem $\mathcal{R}$.

Because the optimal deterministic contract satisfies all neglected constraints, it is also a solution to the original problem $\mathcal{P}$, and this establishes Theorem 1 .

Remark: If condition $\mathrm{R}$ does not hold, Theorem 1 may fail, and a stochastic contract which does condition on the buyer's ex ante type may be optimal. An example is presented in Heumann (2013) who considers a setup where the seller controls both the design of the contract and the sequential revelation of the buyer's private information, and has to respect ex post participation constraints. This yields an optimal, multi-period information structure in which the analog to our regularity condition $\mathrm{R}$ is violated and for which stochastic non-static contracts are optimal. ${ }^{30}$ Finally, we note that Theorem 1 may also fail when the seller, instead of a single unit, may sell an arbitrary quantity of the good and costs or benefits are non-linear in quantity.

\section{Conclusion}

This paper shows that introducing ex post individual rationality constraints in a framework with dynamic private information eliminates the value of eliciting the agent's infor-

\footnotetext{
${ }^{30}$ Bergemann and Wambach (2013) also construct a sequential disclosure policy and a mechanism which does sequentially screen the buyer, and which does respect stronger than ex ante participation constraints. Compared with us, these authors use a weaker concept of ex post individual rationality which only requires ex post individual rationality conditional on the information disclosed.
} 
mation sequentially. Instead, a simple contract that conditions only on the agent's final information is optimal. ${ }^{31}$

In the context of distance sales contracts, our analysis confirms that withdrawal rights are an effective regulatory tool for achieving a level playing field between internet shops and traditional brick and mortar stores. The welfare effects of withdrawal rights are however ambiguous and crucially depend on the details of the distributions of ex ante and ex post types. In line with the rationale behind the EU-regulation discussed in the introduction, we consider a setting in which the buyer rather than the seller has private information. As a result, the seller does not have an incentive to offer a withdrawal right voluntarily. It is however well-known that such incentives arise when the seller has private information, because return rights may signal high quality to uninformed consumers. ${ }^{32}$ When the seller possesses private information about quality and the buyer about his tastes, the interesting question arises to what extent legally mandated withdrawal rights interfere with the incentives to signal quality by return policies. Moreover, by focusing on a bilateral relationship, we also abstract from the natural possibility that the private information of a buyer may be informative about the willingness to pay of other consumers. Such interdependencies between buyers may give rise to an endogenous common value effect that the seller's outside option depends on the buyer's private information. Addressing these extensions is beyond the scope of the current paper, but their exploration are worthwhile avenues for future research.

Our techniques and results extend readily to settings with multiple buyers. For the unit good auction model in which the buyers' private information about their valuation arrives sequentially, Esö and Szentes (2007b) show that, when there are only ex ante individual rationality constraints, the optimal mechanism is a sequential auction where the winner's

\footnotetext{
${ }^{31}$ In a similar vein, Kovac and Krähmer (2013) show that a static mechanism can be optimal in a sequential optimal delegation environment in which, unlike in the current work, monetary transfers between the principal and the agent are not feasible.

${ }^{32}$ In the context of adverse selection see Grossman (1981) for formalizing this argument for warrantees in general and Inderst and Ottaviani (2013) for a recent application to return rights in particular. Mann and Wissink (1990) explicitly compare money-back guarantees to replacement warrantees when the seller has superior information due to moral hazard. See also Moorthy and Srinivasan (1995), who argue that performance warrantees, in contrast to money-back guarantees, are not particularly good signals of product quality.
} 
price depends not only on the final bid but also on information provided by bidders in an initial round. In contrast, it follows from our result that the optimal mechanism with ex post individual rationality constraints is equivalent to the static Myerson (1981) auction that is optimal for the seller when he faces the buyers after they received all their private information. Hence, with ex post individual rationality constraints, the optimal mechanism is simpler, and the seller does not benefit from a sequential mechanism.

\section{A Appendix}

Proof of Lemma 1 Since the "vice versa" statement follows directly from the revelation principle, we prove the lemma only in one direction. We use the following lemma which characterizes incentive compatibility in period 2. (The proof is standard and therefore omitted.)

Lemma A.1 A direct contract (x,t) is incentive compatible in period 2, i.e. satisfies (2), if and only if for all $i \in I$, the functions $v_{i}$ as given by (1) are absolutely continuous and

$$
\begin{gathered}
x_{i}(\theta) \text { is increasing in } \theta, \\
v_{i}(\theta)=\int_{0}^{\theta} x_{i}(z) d z+v_{i}(0) .
\end{gathered}
$$

In light of the lemma, consider an incentive compatible, deterministic contract $(\mathbf{x}, \mathbf{t})$. Because the contract is deterministic, condition $\left(M O N_{i}\right)$ implies the existence of a cutoff $R_{i} \in[0,1]$ so that $x_{i}(\theta)=\mathbf{1}_{\left[R_{i}, 1\right]}(\theta)$ a.e., where $\mathbf{1}$ denotes the indicator function. Moreover, let $F_{i}=-v_{i}(0)$, and define $(\mathbf{F}, \mathbf{R})=\left(\left(F_{1}, R_{1}\right), \ldots,\left(F_{i}, R_{i}\right), \ldots,\left(F_{n}, R_{n}\right)\right)$. By $(R E)$ and (8), the buyer's utility from submitting report $j$ in period 1 under the direct contract is the same as choosing $\left(F_{j}, R_{j}\right)$ from the menu of option contracts. Therefore, because $(\mathbf{x}, \mathbf{t})$ is incentive compatible in period 1 , the menu $(\mathbf{F}, \mathbf{R})$ is incentive compatible and implements the same outcome as the direct contract.

Q.E.D.

Proof of Lemma 2: Follows directly from Courty and Li (2000).

Proof of Proposition 1: Follows from the discussion in the main text.

Proof of Proposition 2: Follows from the discussion in the main text.

Proof of Lemma 3: Follows from the discussion in the main text. 
Proof of Proposition 3: Lemma 3 implies that the static menu with $\left(F_{i}, R_{i}\right)=\left(0, \bar{R}_{J^{*}}\right)$ for all $i \in I$ solves the relaxed version of problem $\mathcal{P}^{J^{*}}$, where we ignore the constraint $\left(I C_{J}\right)$. Let $W^{J^{*}}$ represent the objective of $\mathcal{P}^{J^{*}}$ evaluated at the static menu with $\left(F_{i}, R_{i}\right)=$ $\left(0, \bar{R}_{J^{*}}\right)$ for all $i \in I$. Now suppose, in contradiction to our claim, that the static menu is not a solution to the original problem $\mathcal{P}^{J^{*}}$. Then there is a non-empty set $\bar{I} \subset I \backslash J^{*}$ of ex ante types for which the static menu violates constraint $\left(I C_{J}\right)$. Also the value of program $\mathcal{P}^{J^{*}}$ must be less than $W^{J^{*}}$, because $W^{J^{*}}$ is the value of the relaxed program. But the static menu with $\left(F_{i}, R_{i}\right)=\left(0, \bar{R}_{J^{*}}\right)$ for all $i \in I$ satisfies all constraints of program $\mathcal{P}^{J^{*} \cup \bar{I}}$. It yields the seller strictly more than $W^{J^{*}}$, because she now also receives a positive payoff from ex ante types $i \in \bar{I}$. Hence, it is not optimal for the seller to send the good only to ex ante types in $J^{*}$, a contradiction.

Q.E.D.

Proof of Lemma 4: Recall that problem $\mathcal{P}$ is given as

$$
\mathcal{P}: \quad \max _{(\mathbf{x}, \mathbf{t})} \sum_{i \in I} p_{i} w_{i} \quad \text { s.t. } \quad(2),(3),(4)
$$

We first show that the constraints $(2),(3),(4)$ are equivalent to the constraints $\left(M O N_{i}\right)$, $\left(I C_{i j}^{\mathbf{v}}\right),\left(I R_{i}\right)$ as stated in Lemma 4 and $(R E)$ as stated in Lemma A.1. Indeed, by Lemma A.1, (2) is equivalent to $\left(M O N_{i}\right)$ and $(R E)$. By $(R E)$, we obtain

$$
\begin{aligned}
\int_{0}^{1} v_{j}(\theta) d G_{i}(\theta)= & \int_{0}^{1} \int_{0}^{\theta} x_{j}(z) d z g_{i}(\theta) d \theta+v_{j}(0) \\
= & -\left[\int_{0}^{\theta} x_{j}(z) d z \cdot\left[1-G_{i}(\theta)\right]\right]_{0}^{1} \\
& \quad+\int_{0}^{1} x_{j}(\theta)\left[1-G_{i}(\theta)\right] d \theta+v_{j}(0) \\
= & \int_{0}^{1} x_{j}(\theta)\left[1-G_{i}(\theta)\right] d \theta+v_{j}(0),
\end{aligned}
$$

where we have used integration by parts in the second line. Thus, since $u_{j i}=\int_{0}^{1} v_{j}(\theta) d G_{i}(\theta)$, (22) implies that (3) is equivalent to $\left(I C_{i j}^{\mathbf{v}}\right)$. Moreover, because $x_{i}$ is non-negative, $(R E)$ implies that $v_{i}(\theta)$ is increasing in $\theta$, and hence (4) is equivalent to $\left(I R_{i}\right)$. In sum, this shows that (2), (3), (4) are equivalent to $\left(M O N_{i}\right),\left(I C_{i j}^{\mathbf{v}}\right),\left(I R_{i}\right)$, and $(R E)$.

Finally, we can eliminate constraint $(R E)$ by inserting it in the objective: (22) for $j=i$ yields

$$
\int_{0}^{1} v_{i}(\theta) d G_{i}(\theta)=\int_{0}^{1} x_{i}(\theta) h_{i}(\theta) d G_{i}(\theta)+v_{i}(0)
$$


Plugging this in (6) yields

$$
w_{i}=\int_{0}^{1}\left[\theta-c-h_{i}(\theta)\right] x_{i}(\theta) d G_{i}(\theta)-v_{i}(0),
$$

and hence, we obtain the objective as stated in Lemma 4.

Q.E.D.

Proof of Lemma 5: Follows from the discussion in the main text.

Proof of Lemma 6: Follows from the discussion in the main text.

Proof of Lemma 7: For a directed set $C \subseteq\left\{(i, j) \in I^{2} \mid i \neq j\right\}$ of constraints, we define the sets

$$
I_{C}^{-}=\{i \in I \mid(i, j) \in C\} \quad \text { and } \quad I_{C}^{+}=\{j \in I \mid(i, j) \in C\}
$$

Observe that $I_{C}^{-} \cap I_{C}^{+}=\emptyset$, because $C$ is directed. If $C$ is directed, $\Psi_{k}$ boils down to

$$
\Psi_{k}(\theta, C, \lambda)= \begin{cases}p_{k}\left[\theta-c-h_{k}(\theta)\right] & \text { if } k \notin I_{C}^{-} \cup I_{C}^{+} \\ p_{k}\left[\theta-c-h_{k}(\theta)\right]-\sum_{j:(k, j) \in C} \lambda_{k j} h_{k}(\theta) & \text { if } \quad k \in I_{C}^{-} \\ p_{k}\left[v-\theta-h_{k}(\theta)\right]+\sum_{i:(i, k) \in C} \lambda_{i k} h_{i k}(\theta) & \text { if } \quad k \in I_{C}^{+} .\end{cases}
$$

Because the hazard rate $h_{k}(\theta)$ is decreasing and $p_{k}[\theta-c]$ is strictly increasing, it follows that $p_{k}\left[\theta-c-h_{k}(\theta)\right]$ is strictly increasing. This establishes that $\Psi_{k}(\theta, C, \lambda)$ is strictly increasing in $\theta$ for $k \notin I_{C}^{-} \cup I_{C}^{+}$. In addition, $\lambda_{k j} \leq 0$ and decreasing cross hazard rates $h_{k j}(\theta)$ imply that $\sum_{i:(i, k) \in C} \lambda_{i k} h_{i k}(\theta)$ is increasing in $\theta$. Hence, $\Psi_{k}(\theta, C, \lambda)$ is strictly increasing in $\theta$ also for $k \in I_{C}^{+}$. Finally, to see that $\Psi_{k}(\theta, C, \lambda)$ is strictly increasing in $\theta$ also for $k \in I_{C}^{-}$, first re-write $\Psi_{k}(\theta, C, \lambda)$ for $k \in I_{C}^{-}$as

$$
\Psi_{k}(\theta, C, \lambda)=p_{k}[\theta-c]-\left(p_{k}+\sum_{j:(k, j) \in C} \lambda_{k j}\right) h_{k}(\theta) .
$$

By assumption, $\Psi_{k}(\hat{\theta}, C, \lambda)=0$ for some $\hat{\theta} \in[c, 1]$. For $k \in I_{C}^{-}$, this implies that

$$
p_{k}+\sum_{j:(k, j) \in C} \lambda_{k j}=\frac{p_{k}[\hat{\theta}-c]}{h_{k}(\hat{\theta})} \geq 0 .
$$

The decreasing hazard rate $h_{k}(\cdot)$ therefore implies that $\left(p_{k}+\sum_{j:(k, j) \in C} \lambda_{k j}\right) h_{k}(\theta)$ is decreasing. Due to the term $p_{k}[\theta-c]$, it then follows that $(27)$ is strictly increasing in $\theta$. Q.E.D.

Proof of Lemma 8: The statement that if $C$ is directed and permits a static solution, then the optimal static contract is a solution to $\mathcal{R}^{0}(C)$ follows from the main text. Because 
the optimal static contract exhibits increasing selling schedules and trivially satisfies $\left(I C_{i j}^{0}\right)$ for all $i, j \in I$, it is also a solution to the more constrained problem $\mathcal{P}^{0}$.

Q.E.D.

Proof of Lemma 9: We begin by proving the auxiliary claim

$$
\bar{R} \in\left[\theta_{n}, \theta_{1}\right]
$$

Since densities $g_{i}(\theta)=G_{i}^{\prime}(\theta)$ exist, $\bar{R}$ as a solution to $(7)$ satisfies the first order condition

$$
1-\sum_{i \in I} p_{i} G_{i}(\bar{R})-(\bar{R}-c) \sum_{i \in I} p_{i} g_{i}(\bar{R})=0 .
$$

Now suppose that, contrary to the claim, $\bar{R}<\theta_{n}$. (Similar arguments apply to the claim $\bar{R}>\theta_{1}$.) Then, because the hazard rate is decreasing and since $\bar{R}<\theta_{n} \leq \theta_{i}$ for all $i \in I$, (16) implies that $\bar{R}<\theta_{i}=c+h_{i}\left(\theta_{i}\right)<c+h_{i}(\bar{R})$ so that $(\bar{R}-c) g_{i}(\bar{R})<1-G_{i}(\bar{R})$. Multiply this inequality with $p_{i}$ and sum over $i \in I$ to get $(\bar{R}-c) \sum_{i \in I} p_{i} g_{i}(\bar{R})<1-\sum_{i \in I} p_{i} G_{i}(\bar{R})$, a contradiction to (30). This establishes (29) and directly implies that $C^{*}$ is non-empty.

We now turn to the core of the proof and show (18) for the set $C^{*}$. We begin by writing the system of equations $\Psi_{k}\left(\bar{R}, C^{*}, \lambda\right)=0, k \in I$, in the $L$ unknowns $\lambda_{i j},(i, j) \in C^{*}$, in matrix notation. Let $\lambda=\left(\lambda_{1}, \ldots, \lambda_{L}\right) \in \mathbb{R}^{L}$ be the (column) vector consisting of the multipliers $\lambda_{i j},(i, j) \in C^{*}$. Moreover, define the (column) vector $b=\left(b_{1}, \ldots, b_{n}\right)$ by

$$
b_{k}=p_{k} g_{k}(\bar{R})(\bar{R}-c)-p_{k}\left[1-G_{k}(\bar{R})\right]
$$

Observe that by $(25)$ and the definition of $C^{*}$, we have $I_{C^{*}}^{-}=I^{-}$and $I_{C^{*}}^{+}=I^{+}$. To simplify notation, we omit the arguments $\bar{R}$ and $C^{*}$ in what follows. Therefore, by (26), after multiplying $\Psi_{k}(\lambda)=0$ by $g_{k}$, we obtain that

$$
\begin{array}{ll}
k \in I^{-}: & \Psi_{k}(\lambda)=0 \quad \Leftrightarrow \sum_{j:(k, j) \in C^{*}}\left[1-G_{k}\right] \lambda_{k j}=b_{k}, \\
k \in I^{+}: & \Psi_{k}(\lambda)=0 \quad \Leftrightarrow \sum_{i:(i, k) \in C^{*}}-\left[1-G_{i}\right] \lambda_{i k}=b_{k} .
\end{array}
$$

Because $I^{-} \cup I^{+}=I,(32)$ and (33) for $k=1, \ldots, n$ writes

$$
A \lambda=b
$$

for the following $n \times L$ matrix $A$ : Let $a_{\ell}$ be the $\ell^{t h}$ column vector of $A \in \mathbb{R}^{n \times L}$. Consider an index $\ell$ with $\lambda_{\ell}=\lambda_{i j}$. Then, by inspection of (32) and (33), the $i^{\text {th }}$ row of $a_{\ell}$ is equal 
to $1-G_{i}$ and the $j^{\text {th }}$ row of $a_{\ell}$ is equal to $-\left(1-G_{i}\right)$ and all other rows of $a_{\ell}$ are equal to 0 :

$$
a_{\ell}=\left(\begin{array}{c}
0 \\
\vdots \\
1-G_{i} \\
\vdots \\
-\left(1-G_{i}\right) \\
\vdots \\
0
\end{array}\right) \leftarrow j
$$

Therefore, $C^{*}$ satisfies (18) if and only if there is a $\lambda \leq 0$ (componentwise) so that $A \lambda=b$. By Farkas' lemma this is equivalent to:

$$
\text { for all } y \in \mathbb{R}^{n} \text { there is an } \ell \in\{1, \ldots, L\} \text { so that } a_{\ell} \cdot y>0 \text { or } b \cdot y \geq 0 \text {, }
$$

where "." indicates the scalar product. To prove (36), it is sufficient to show that $a_{\ell} \cdot y \leq 0$ for all $\ell \in\{1, \ldots, L\}$ implies

$$
b \cdot y \geq 0
$$

To this aim, suppose $a_{\ell} \cdot y \leq 0$ for all $\ell \in\{1, \ldots, L\}$. Because each $(i, j) \in C^{*}$ is associated with some $\ell$, it follows that for each $(i, j) \in C^{*}$ there exists an $\ell$ such that $a_{\ell} \cdot y=G_{i}\left(y_{i}-y_{j}\right) \leq 0$. Consequently, $y_{i} \leq y_{j}$ for all $(i, j) \in C^{*}$. Since $C^{*}=I^{-} \times I^{+}$, it follows:

$$
\max _{i \in I^{-}} y_{i} \leq \min _{j \in I^{+}} y_{j}
$$

Now observe that $b_{k} \lesseqgtr 0$ if and only if $\bar{R} \lesseqgtr \theta_{k} \cdot{ }^{33}$ By definition of $I^{-}$and $I^{+}$, this implies that $b_{i} \leq 0$ if $i \in I^{-}$, and $b_{j}>0$ if $j \in I^{+}$. Hence,

$$
b \cdot y=\sum_{i \in I^{-}} b_{i} y_{i}+\sum_{j \in I^{+}} b_{j} y_{j} \geq \max _{i \in I^{-}} y_{i} \cdot \sum_{i \in I^{-}} b_{i}+\min _{j \in I^{+}} y_{j} \cdot \sum_{j \in I^{+}} b_{j} \geq \max _{i \in I^{-}} y_{i} \cdot \sum_{k \in I} b_{k},
$$

where the last inequality follows by (38). Finally observe that the final term is zero, because $\sum_{k \in I} b_{k}=0$ by (30). This establishes (37).

Q.E.D.

\footnotetext{
${ }^{33}$ To see this, recall that $\theta_{k}$ is given as the root of the function $p_{k}\left[\theta-c-h_{k}(\theta)\right]$. Because of the monotone hazard rate, this function is increasing, and so we have that $\bar{R} \leq \theta_{k}$ if and only if $p_{k}\left[\bar{R}-c-h_{k}(\bar{R})\right] \leq$ $0 \Leftrightarrow b_{k} \leq 0$.
} 
Proof of Proposition 4: By the Kuhn-Tucker theorem, we have to show that there are multipliers $\lambda_{i j} \leq 0,(i, j) \in C^{*}$, and $\mu_{k} \leq 0, k \in I$, so that $(\overline{\mathbf{x}}, \overline{\mathbf{v}})$ maximizes the Lagrangian

$$
\begin{aligned}
\mathcal{L}= & \sum_{k \in I}\left[\int_{0}^{1} p_{k}\left[\theta-c-h_{k}(\theta)\right] x_{k}(\theta) g_{k}(\theta) d \theta-p_{k} v_{k}(0)\right] \\
& -\sum_{(i, j) \in C^{*}} \lambda_{i j}\left[\int_{0}^{1}\left[x_{i}(\theta)-x_{j}(\theta)\right]\left[1-G_{i}(\theta)\right] d \theta+v_{i}(0)-v_{j}(0)\right]-\sum_{k \in I} \mu_{k} v_{k}(0) \\
= & \sum_{k \in I} \int_{0}^{1}\left[p_{k}\left[\theta-c-h_{k}(\theta)\right]-\sum_{j:(k, j) \in C^{*}} \lambda_{k j} h_{k}(\theta)+\sum_{i:(i, k) \in C^{*}} \lambda_{i k} h_{i, k}(\theta)\right] x_{k}(\theta) g_{k}(\theta) d \theta \\
& -\sum_{k \in I}\left\{p_{k}+\sum_{j:(k, j) \in C^{*}} \lambda_{k j}-\sum_{i:(i, k) \in C^{*}} \lambda_{i k}+\mu_{k}\right\} v_{k}(0),
\end{aligned}
$$

where $\lambda_{i j}=0$ or $\mu_{k}=0$ only if the respective constraints are not binding. Now, let $\lambda_{i j} \leq 0$, $(i, j) \in C^{*}$ be the multipliers from the proof of Lemma 9 that solve $\Psi_{k}\left(\bar{R}, C^{*}, \lambda\right)=0$ for all $k \in I$ and define

$$
\mu_{k}=\left\{\begin{array}{lll}
-p_{k}-\sum_{j:(k, j) \in C^{*}} \lambda_{k j} & \text { if } & k \in I^{-} \\
-p_{k}+\sum_{i:(i, k) \in C^{*}} \lambda_{i k} & \text { if } & k \in I^{+}
\end{array} .\right.
$$

Then the curly brackets in (41) are zero, and the Lagrangian $\mathcal{L}$ is identical to the Lagrangian for the problem $\mathcal{R}^{0}(C)$, which, by Lemmata 8 and 9 , is maximized by the optimal static contract. Therefore, $(\overline{\mathbf{x}}, \overline{\mathbf{v}})$ maximizes $\mathcal{L}$. It remains to be shown that $\mu_{k} \leq 0$. Since $\lambda_{i k} \leq 0$, the claim is trivial for $k \in I^{+}$. For $k \in I^{-}$, recall from (28) in the proof of Lemma 7 that $-p_{k}-\sum_{j:(k, j) \in C^{*}} \lambda_{k j} \leq 0$. This completes the proof.

Q.E.D.

\section{References}

Baron, D. and D. Besanko (1984). "Regulation and Information in a Continuing Relationship." Information Economics and Policy 1, 267-302.

Baron, D. and R. Myerson (1982). "Regulating a Monopolist with Unknown Costs." Econometrica 50, 911-930.

Battaglini, M. (2005). "Long-Term Contracting with Markovian Consumers." American Economic Review 95, 637-658. 
Battaglini, M. and R. Lamba (2014). "Optimal Dynamic Contracting: the First-Order Approach and Beyond." mimeo.

Bergemann, D. and A. Wambach (2013). "Sequential Information Disclosure in Auctions." mimeo.

Boleslavsky, R. and M. Said (2013). "Progressive Screening: Long-Term Contracting with a Privately Known Stochastic Process." Review of Economic Studies 80, 1-34.

Courty, P. and H. Li (2000). "Sequential Screening." Review of Economic Studies 67, $697-717$.

Dai, C., T. R. Lewis, and G. Lopomo (2006). "Delegating Management to Experts." RAND Journal of Economics 37, 503-520.

Esö, P. and B. Szentes (2007a). "The Price of Advise." RAND Journal of Economics $38,863-880$.

Esö, P. and B. Szentes (2007b). "Optimal Information Disclosure in Auctions and the Handicap Auction." Review of Economic Studies 74, 705-731.

Heumann, T. (2013). "Sequential Mechanism Design with Ex-Post Participation Constraint." mimeo.

Hoffmann, F. and R. Inderst (2011). "Presale Information." Journal of Economic Theory $146,2333-2355$.

Gresik, T. (1991). "Ex Ante Efficient, Ex Post Individually Rational Trade." Journal of Economic Theory 53, 131-145.

Grossman, S. J.(1981). "The Informational Role of Warranties and Private Disclosure about Product Quality." Journal of Law and Economics 24, 461-483.

Inderst, R. and M. Ottaviani (2013). "Sales Talk, Cancellation Terms and the Role of Consumer Protection." The Review of Economic Studies 80, 1002-1026

Inderst, R. and M. Peitz (2012). "Informing Consumers about Their Own Preferences." International Journal of Industrial Organization 30, 417-428. 
Kovac, E. and D. Krähmer. (2013). "Optimal Sequential Delegation.” mimeo.

Krähmer, D. and R. Strausz (2011). "Optimal Procurement Contracts with Pre-Project Planning." Review of Economic Studies 78, 1015-1041.

Luenberger, F. (1969). Optimization by Vector Space Methods., John Wiley \& Sons: New York.

Mann, D.P. and Wissink, J.P.(1990). "Money-Back Warranties vs. Replacement Warranties: A Simple Comparison." American Economic Review Papers and Proceedings 80, 432-436.

Moorthy, S. and K. Srinivasan (1995). "Signaling Quality with a Money-Back Guarantee: The Role of Transaction Costs." Management Science 14, 442-466.

Myerson, R. (1981). "Optimal Auction Design." Mathematics of Operations Research 6, 58-73.

Myerson, R. (1986). "Multistage Games with Communication." Econometrica 54, 32358.

Nocke, V., Peitz, M., and F. Rosar (2011). "Advance-Purchase Discounts as a Price Discrimination Device." Journal of Economic Theory 146, 141-162.

Pavan, A., I. Segal, and J. Toikka (2014). "Dynamic Mechanism Design: A Myersonian Approach" Econometrica 82, 601-653.

Riley, J. and R. Zeckhauser (1983). "Optimal Selling Strategies: When to Haggle, When to Hold Firm." Quarterly Journal of Economics 98, 267-289.

Sappington, D. E. M. (1983). "Limited liability contracts between principal and agent." Journal of Economic Theory 29, 1-21.

Strausz, R. (2006). "Deterministic versus Stochastic Mechanisms Principal-Agent Models." Journal of Economic Theory 128, 306-314. 


\section{SFB 649 Discussion Paper Series 2014}

For a complete list of Discussion Papers published by the SFB 649, please visit http://sfb649.wiwi.hu-berlin.de.

001 "Principal Component Analysis in an Asymmetric Norm" by Ngoc Mai Tran, Maria Osipenko and Wolfgang Karl Härdle, January 2014.

002 "A Simultaneous Confidence Corridor for Varying Coefficient Regression with Sparse Functional Data" by Lijie Gu, Li Wang, Wolfgang Karl Härdle and Lijian Yang, January 2014.

003 "An Extended Single Index Model with Missing Response at Random" by Qihua Wang, Tao Zhang, Wolfgang Karl Härdle, January 2014.

004 "Structural Vector Autoregressive Analysis in a Data Rich Environment: A Survey" by Helmut Lütkepohl, January 2014.

005 "Functional stable limit theorems for efficient spectral covolatility estimators" by Randolf Altmeyer and Markus Bibinger, January 2014.

006 "A consistent two-factor model for pricing temperature derivatives" by Andreas Groll, Brenda López-Cabrera and Thilo Meyer-Brandis, January 2014.

007 "Confidence Bands for Impulse Responses: Bonferroni versus Wald" by Helmut Lütkepohl, Anna Staszewska-Bystrova and Peter Winker, January 2014.

008 "Simultaneous Confidence Corridors and Variable Selection for Generalized Additive Models" by Shuzhuan Zheng, Rong Liu, Lijian Yang and Wolfgang Karl Härdle, January 2014.

009 "Structural Vector Autoregressions: Checking Identifying Long-run Restrictions via Heteroskedasticity" by Helmut Lütkepohl and Anton Velinov, January 2014.

010 "Efficient Iterative Maximum Likelihood Estimation of HighParameterized Time Series Models" by Nikolaus Hautsch, Ostap Okhrin and Alexander Ristig, January 2014.

011 "Fiscal Devaluation in a Monetary Union" by Philipp Engler, Giovanni Ganelli, Juha Tervala and Simon Voigts, January 2014.

012 "Nonparametric Estimates for Conditional Quantiles of Time Series" by Jürgen Franke, Peter Mwita and Weining Wang, January 2014.

013 "Product Market Deregulation and Employment Outcomes: Evidence from the German Retail Sector" by Charlotte Senftleben-König, January 2014.

014 "Estimation procedures for exchangeable Marshall copulas with hydrological application" by Fabrizio Durante and Ostap Okhrin, January 2014.

015 "Ladislaus von Bortkiewicz - statistician, economist, and a European intellectual" by Wolfgang Karl Härdle and Annette B. Vogt, February 2014.

016 "An Application of Principal Component Analysis on Multivariate TimeStationary Spatio-Temporal Data" by Stephan Stahlschmidt, Wolfgang Karl Härdle and Helmut Thome, February 2014.

017 "The composition of government spending and the multiplier at the Zero Lower Bound" by Julien Albertini, Arthur Poirier and Jordan RoulleauPasdeloup, February 2014.

018 "Interacting Product and Labor Market Regulation and the Impact of Immigration on Native Wages" by Susanne Prantl and Alexandra SpitzOener, February 2014.

\section{SFB 649, Spandauer Straße 1, D-10178 Berlin http://sfb649.wiwi.hu-berlin.de}

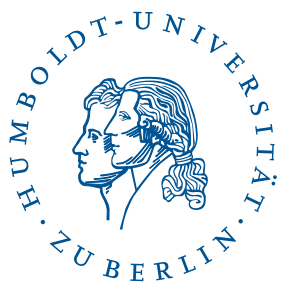




\title{
SFB 649 Discussion Paper Series 2014
}

\author{
For a complete list of Discussion Papers published by the SFB 649, \\ please visit http://sfb649.wiwi.hu-berlin.de.
}

019 "Unemployment benefits extensions at the zero lower bound on nominal interest rate" by Julien Albertini and Arthur Poirier, February 2014.

020 "Modelling spatio-temporal variability of temperature" by Xiaofeng Cao, Ostap Okhrin, Martin Odening and Matthias Ritter, February 2014.

021 "Do Maternal Health Problems Influence Child's Worrying Status? Evidence from British Cohort Study" by Xianhua Dai, Wolfgang Karl Härdle and Keming Yu, February 2014.

022 "Nonparametric Test for a Constant Beta over a Fixed Time Interval" by Markus Reiß, Viktor Todorov and George Tauchen, February 2014.

023 "Inflation Expectations Spillovers between the United States and Euro Area" by Aleksei Netšunajev and Lars Winkelmann, March 2014.

024 "Peer Effects and Students' Self-Control" by Berno Buechel, Lydia Mechtenberg and Julia Petersen, April 2014.

025 "Is there a demand for multi-year crop insurance?" by Maria Osipenko, Zhiwei Shen and Martin Odening, April 2014.

026 "Credit Risk Calibration based on CDS Spreads" by Shih-Kang Chao, Wolfgang Karl Härdle and Hien Pham-Thu, May 2014.

027 "Stale Forward Guidance" by Gunda-Alexandra Detmers and Dieter Nautz, May 2014.

028 "Confidence Corridors for Multivariate Generalized Quantile Regression" by Shih-Kang Chao, Katharina Proksch, Holger Dette and Wolfgang Härdle, May 2014.

029 "Information Risk, Market Stress and Institutional Herding in Financial Markets: New Evidence Through the Lens of a Simulated Model" by Christopher Boortz, Stephanie Kremer, Simon Jurkatis and Dieter Nautz, May 2014.

030 "Forecasting Generalized Quantiles of Electricity Demand: A Functional Data Approach" by Brenda López Cabrera and Franziska Schulz, May 2014.

031 "Structural Vector Autoregressions with Smooth Transition in Variances The Interaction Between U.S. Monetary Policy and the Stock Market" by Helmut Lütkepohl and Aleksei Netsunajev, June 2014.

032 "TEDAS - Tail Event Driven ASset Allocation" by Wolfgang Karl Härdle, Sergey Nasekin, David Lee Kuo Chuen and Phoon Kok Fai, June 2014.

033 "Discount Factor Shocks and Labor Market Dynamics" by Julien Albertini and Arthur Poirier, June 2014.

034 "Risky Linear Approximations" by Alexander Meyer-Gohde, July 2014

035 "Adaptive Order Flow Forecasting with Multiplicative Error Models" by Wolfgang Karl Härdle, Andrija Mihoci and Christopher Hian-Ann Ting, July 2014

036 "Portfolio Decisions and Brain Reactions via the CEAD method" by Piotr Majer, Peter N.C. Mohr, Hauke R. Heekeren and Wolfgang K. Härdle, July 2014

037 "Common price and volatility jumps in noisy high-frequency data" by Markus Bibinger and Lars Winkelmann, July 2014

038 "Spatial Wage Inequality and Technological Change" by Charlotte Senftleben-König and Hanna Wielandt, August 2014

039 "The integration of credit default swap markets in the pre and postsubprime crisis in common stochastic trends" by Cathy Yi-Hsuan Chen, Wolfgang Karl Härdle, Hien Pham-Thu, August 2014

\section{SFB 649, Spandauer Straße 1, D-10178 Berlin http://sfb649.wiwi.hu-berlin.de}

This research was supported by the Deutsche Forschungsgemeinschaft through the SFB 649 "Economic Risk".

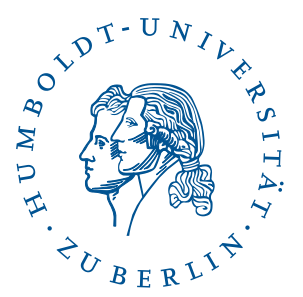




\section{SFB 649 Discussion Paper Series 2014}

For a complete list of Discussion Papers published by the SFB 649, please visit http://sfb649.wiwi.hu-berlin.de.

040 "Localising Forward Intensities for Multiperiod Corporate Default" by Dedy Dwi Prastyo and Wolfgang Karl Härdle, August 2014.

041 "Certification and Market Transparency" by Konrad Stahl and Roland Strausz, September 2014.

042 "Beyond dimension two: A test for higher-order tail risk" by Carsten Bormann, Melanie Schienle and Julia Schaumburg, September 2014.

043 "Semiparametric Estimation with Generated Covariates" by Enno Mammen, Christoph Rothe and Melanie Schienle, September 2014.

044 "On the Timing of Climate Agreements" by Robert C. Schmid and Roland Strausz, September 2014.

045 "Optimal Sales Contracts with Withdrawal Rights" by Daniel Krähmer and Roland Strausz,, September 2014. 